\title{
WestVirginiaUniversity
}

THE RESEARCH REPOSITORY @ WVU

Graduate Theses, Dissertations, and Problem Reports

2016

\section{Large deflection analysis of composite beams}

\author{
Sai Manohari Kancharla
}

Follow this and additional works at: https://researchrepository.wvu.edu/etd

\section{Recommended Citation}

Kancharla, Sai Manohari, "Large deflection analysis of composite beams" (2016). Graduate Theses, Dissertations, and Problem Reports. 5929.

https://researchrepository.wvu.edu/etd/5929

This Thesis is protected by copyright and/or related rights. It has been brought to you by the The Research Repository @ WVU with permission from the rights-holder(s). You are free to use this Thesis in any way that is permitted by the copyright and related rights legislation that applies to your use. For other uses you must obtain permission from the rights-holder(s) directly, unless additional rights are indicated by a Creative Commons license in the record and/ or on the work itself. This Thesis has been accepted for inclusion in WVU Graduate Theses, Dissertations, and Problem Reports collection by an authorized administrator of The Research Repository @ WVU. For more information, please contact researchrepository@mail.wvu.edu. 


\title{
Large Deflection Analysis of Composite Beams
}

\author{
Sai Manohari Kancharla \\ Thesis submitted \\ to the Statler College of Engineering and Mineral Resources \\ At the West Virginia University \\ in partial fulfillment of the requirements for the degree of
}

Master of Science in

Mechanical Engineering

Nithi T. Sivaneri, Ph.D., Chair

Ever J. Barbero, Ph.D.

Terence D.Musho, Ph.D.

Department of Mechanical and Aerospace Engineering

\author{
Morgantown, West Virginia
}

2016

Keywords: Composite Materials, Large Deflection, HSDT, Finite Element

Method, Nonlinear Analysis

Copyright 2016 Sai Manohari Kancharla 


\section{ABSTRACT \\ Large Deflection Analysis of Composite Beams \\ Sai Manohari Kancharla}

A beam made of composite material undergoing large deflections is analyzed based on a higher-order shear deformation theory. Composite materials offer several advantages over conventional materials in the form of improved strength to weight ratio, high impact strength, corrosion resistance, and design flexibility. The Euler-Bernoulli beam theory is valid only for small deflections and may be too restrictive in a number of applications. The formulation of the large deflection analysis of composite beams is carried out using the principle of virtual work. The spatial discretization is done using an $h-p$ version finite element method. The nonlinear large deflection equations are solved using an iterative process. Results are presented in the form of deflections as a function of position. 


\section{Acknowledgements}

I would like to sincerely thank my advisor, Dr. Nithi T. Sivaneri, for his advising and teaching right from the beginning of my M.S. program. Thought out my research, he immensely supported me with patience, care and regard. In this journey under him, I feel I've learnt a quite lot in understanding the problem, improving problem solving skills and exploring new methods to solve a problem.

I would also like to thank Dr. Ever J. Barbero, for his constant support and encouragement during my research, graduate technical presentations and industrial visits, Dr. Terence D. Musho, for being my research committee member and rendering his support during my tough times. Also, I would like to extend my sincere regards to Dr. Victor H. Mucino and all the non-teaching staff of department of Mechanical Engineering for their timely support.

I'm fortunate to have friends like Anveeksh, Ranjith who gave a lot of moral support and confidence during my tough phases of life at WVU. From bottom of my heart, I'm indebted to my parents, Hari Babu and Lakshmi Rani and my brother Sai Krishna for their love and strong support at all the times. Finally, I sincerely thank the Almighty for providing all these and being with me all the time. 


\section{Table of Contents}

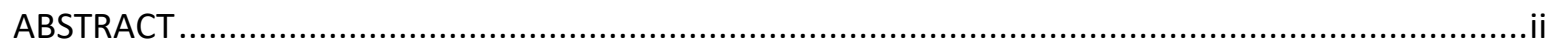

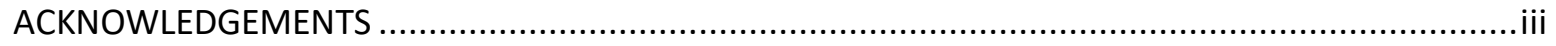

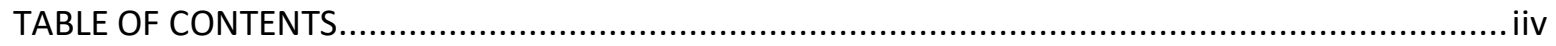

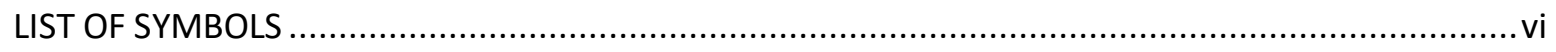

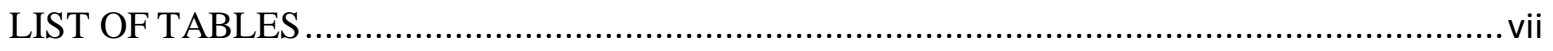

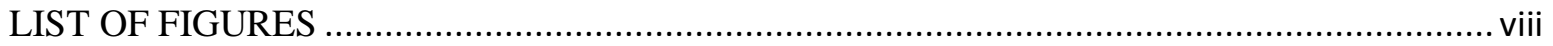

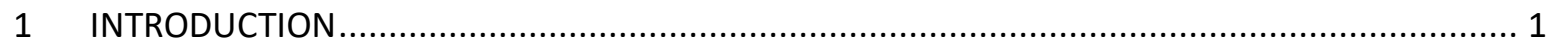

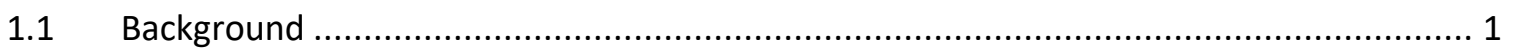

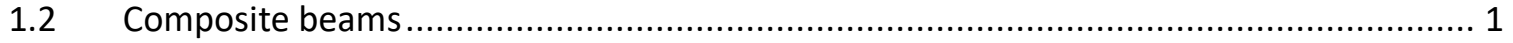

1.3 Problem Statement or Need for Present Research ................................................. 1

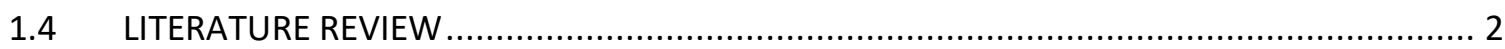

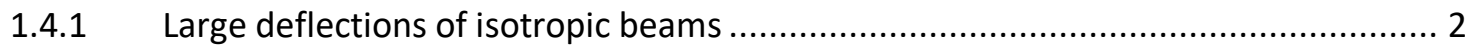

1.4.2 Large deflections of composite beams ......................................................... 2

1.4.3 Reduction of plate theories to beam ........................................................... 3

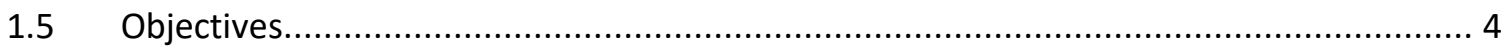

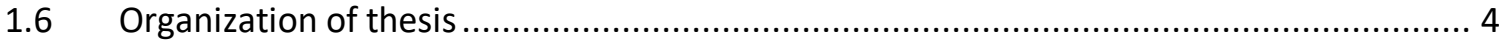

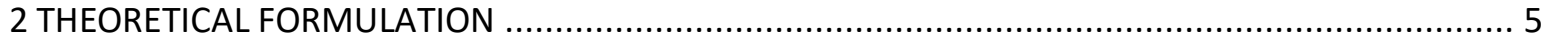

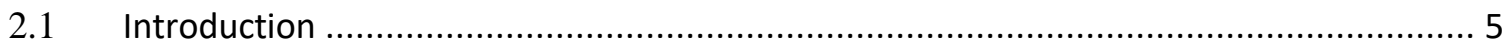

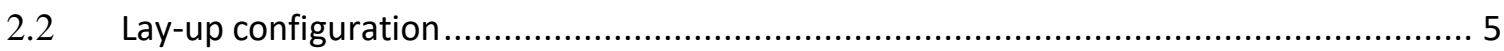

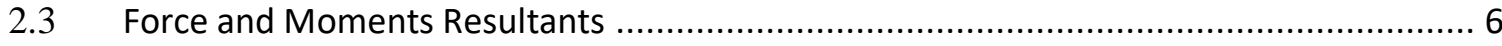

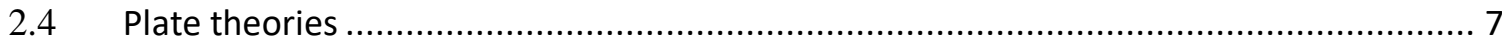

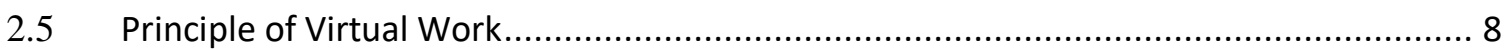

2.5.1 Kinematic Equations of composite plate .............................................................10

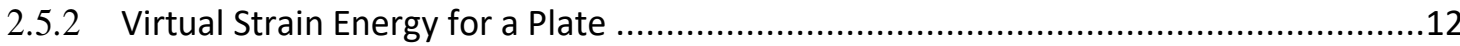

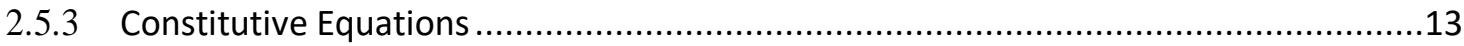

2.5.4 Reduction of Plate Equations to Beams [Nagappan (2004)] ..................................13

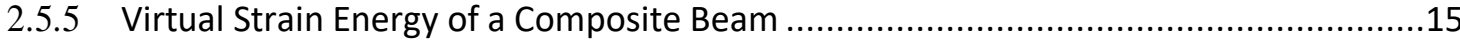

2.5.6 Large Deflection Cylindrical Bending of Composite Plates ......................................17

2.5.7 Virtual Strain Energy for Cylindrical Bending ...........................................................18

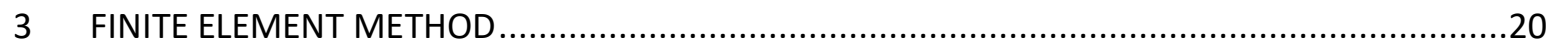




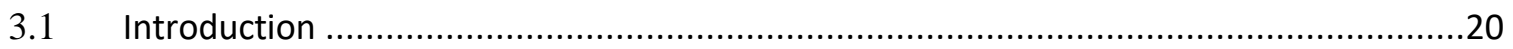

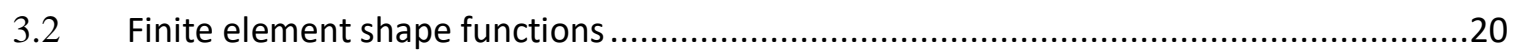

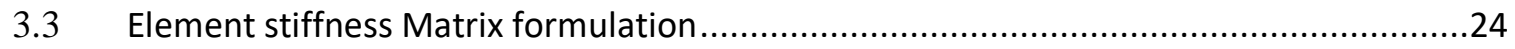

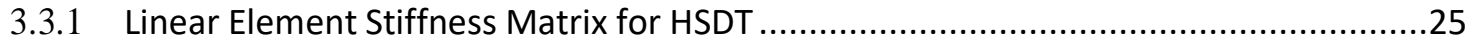

3.3.2 Nonlinear Element Stiffness Matrix for HSDT .........................................................27

3.4 Elemental Stiffness matrix for Cylindrical Bending ..................................................30

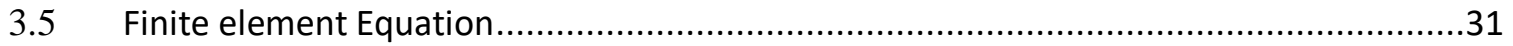

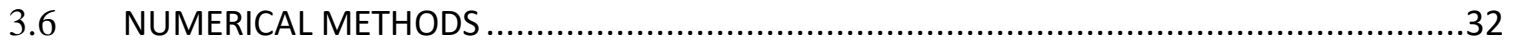

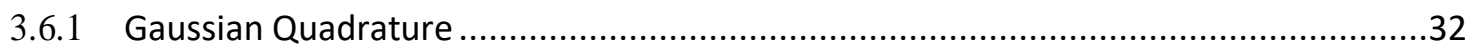

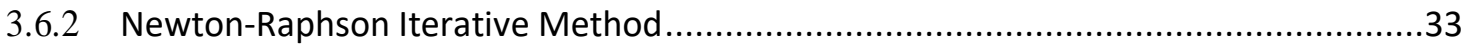

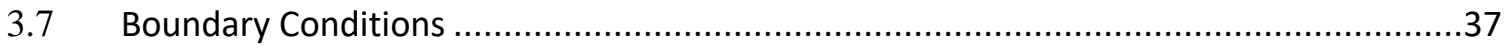

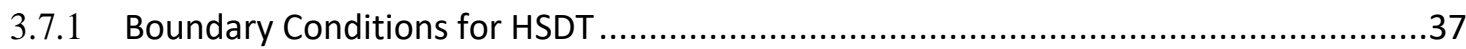

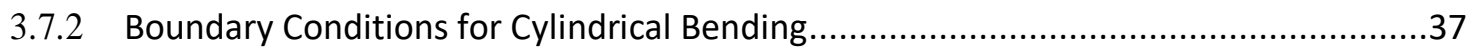

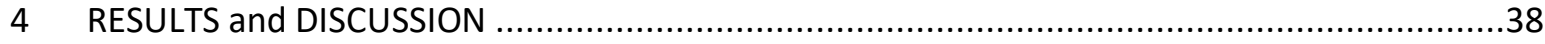

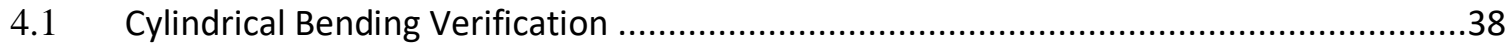

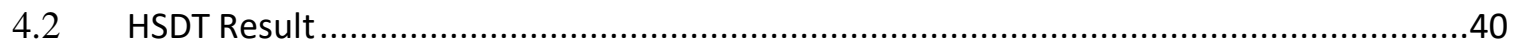

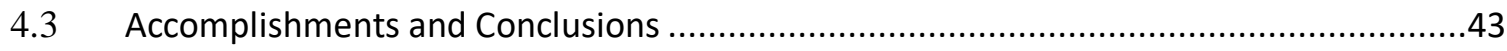

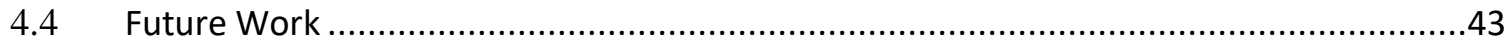

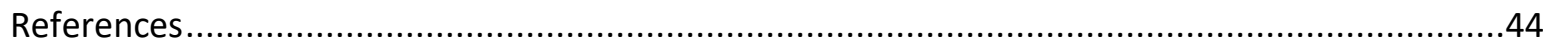




\section{LIST OF SYMBOLS}

[A]

[B]

[D]

E

$[E],[F],[H]$

$h$

$H_{i}, H_{L i}$

$\left[K_{L_{e}}\right]$

$\left[K_{N L_{e}}\right]$

[K]

$L$

$l_{e}$

$n$

$N_{x}, N_{y}, N_{x y}$

$P_{x}, P_{y}, P_{x y}$

$\{q\}$

$\{Q\}$

$t_{k}$

$[T]^{\mathrm{ij}}$

$T_{i j}$

$u$

$u_{0}, v_{0}, w_{0}$

$U$

V

$w_{b}, w_{s}$

$w$

W

$x_{e}$

$X, Y$

$z$

$z_{k}$

$\bar{Z}_{k}$

$\delta()$

$\varepsilon_{x}, \varepsilon_{y}, \varepsilon_{z}$

$\phi_{x}, \phi_{y}$

$\gamma_{x y}, \gamma_{y z}, \gamma_{x z}$

$\xi$

()$^{\mathrm{T}}$

( )', ( )',

()$^{\mathrm{y}}$
- Axial Stiffness Matrix

- Bending-extension Stiffness Matrix (N)

-Bending Stiffness Matrix (Nm)

-Modulusofelasticity $\left(\mathrm{N} / \mathrm{m}^{2}\right)$

-Higher-orderstiffnessmatrices $\left(\mathrm{Nm}^{2}, \mathrm{Nm}^{3}, \mathrm{Nm}^{5}\right)$

-Thicknessofthebeam $(\mathrm{m})$

- Hermitian and Lagrangian Shape Functions

- Linear Stiffness matrix (N/m)

- Nonlinear Stiffness matrix (N/m)

-Global Stiffness matrix (N/m)

-Length of beam (m)

-Length of element (m)

- Number of layers

- In Plane force resultants in xy plane (N/m)

- Higher order stress resultants

- Global displacements vector (m)

- Global load vector $(\mathrm{N})$

- Thickness of kth layer (m)

- Partitions of reduced [ABDEF] matrix

- Elements of reduced [T] matrix

- Axial deflection (m)

- Mid-plane displacements along $\mathrm{x}, \mathrm{y}$, and $\mathrm{z}$ axis, respectively (m)

- Total strain energy $(\mathrm{Nm})$

- Volume (m3)

- Shear and bending components of transverse deflection (m)

- Transverse deflection (m)

- Work done (Nm)

- Element longitudinal axis

- Global Axes

- Thickness coordinate

- Distance to the top of the kth layer from the mid-plane of a laminate $(\mathrm{m})$

- Distance to the mid surface of the kth layer from the mid-plane of a laminate $(\mathrm{m})$

- Variation of ( )

- Normal strains in $x, y$, and $z$ directions respectively

- Rotations about $\mathrm{x}$ and $\mathrm{y}$, respectively

- Engineering shear strains

- Elemental non-dimensional coordinate

- Transpose of ( )

- First and second partial derivatives with respect to $\mathrm{x}$

- Partial derivative with respect to y 


\section{LIST OF TABLES}

Table 3.1: Gauss Quadrature sample points and weights

Table 4.1: Material properties Sun and Chin (1988)

Table 4.2: Geometric properties Sun and Chin (1988)

Table 4.3: Transverse deflections, $w_{0} / h$, of cylindrical bending of a $\left[0_{4} / 90_{4}\right]$ laminate under uniformly distributed transverse load

Table 4.4: Material properties

Table 4.5: Geometric properties

Table4.6: Transverse deflections, $w_{\max }$, of nonlinear and linear of a $\left[90_{8} / 0_{8}\right]$ laminate under uniformly distributed transverse load 


\section{LIST OF FIGURES}

Fig. 2.1: Composite lay-up configuration

Fig. 2.2: Assembly of three laminae into a laminate [Barbero (1998)]

Fig. 2.3: Force and moments resultants on a flat plate [Barbero (1998)]

Fig. 2.4: Deformationof transversenormalforCLPT,FSDTandHSDT[Reddy(1997)]

Fig. 2.5: Transverse load $P_{z}(x, y)$ on a laminated plate

Fig. 3.1: Classification of methods to solve partial differential equations

Fig. 3.2: Finite element beam representation and representation of an element with natural coordinates and three internal nodes

Fig. 4.1: Out-of-plane deflection of $\left[0_{4} / 90_{4}\right]$ laminate subjected to uniform in-plane load $N_{x}=1 \mathrm{lb} / \mathrm{in}$

Fig. 4.2:Load-deflection curve of a pinned-pinned composite beam under transverse load

Fig. 4.3: Load-deflection curve for nonlinear and linear with pinned-pinned edges 


\section{INTRODUCTION}

\subsection{Background}

Large deflection of beams has vital applications in aircraft, aerospace vehicles, and heavy machinery. With the advent in new composite materials, many parts that require improved strength with lesser weight have been dominating the industry demands. In pursuit of such materials, this research is entitled to develop a theory to efficiently test the capability of a composite beam undergoing large deflection, greater than or equal to one tenth the height of beam, due to static loading.

\subsection{Composite beams}

A beam is generally considered a one-dimensional structure as its length is large when compared to its height and width. Composite materials are classified into laminated composites, fibrous composites, and particulate composites. Laminated composites are usually treated as plate elements. This is because composites have their planar dimensions comparatively larger than the thickness. Therefore, to study the behavior of composites, laminate plate theories were developed. When the width of the plate is small compared to the length it is treated as a beam.

\subsection{Problem Statement or Need for Present Research}

The Euler Bernoulli beam bending moment equation is stated as below

$$
M=-E I \frac{d^{2} w}{d x^{2}}
$$

where, $M$ is the bending moment, $E I$ is the flexural rigidity and $\frac{d^{2} w}{d x^{2}}$ is the curvature of the deflected longitudinal axis.

Eq. (1.1) does not hold good for analyzing large scale deflections [Howell and Midha(1995)] many theories are proposed to analyze the large deflections of an isotropic beam. Linear laminate plate theory is shown to be inadequate for analysis of asymmetric composite laminate, even in small deflection range [Sun and Chin (1998)]. Some researchers have analyzed large deflection of composite beams using the First order Shear Deformation Theory (FSDT). The FSDT uses a shear correction factor, which is only an approximation. Therefore, a higherorder theory that could provide a better solution can may be used to formulate the finite element model. In the present research, theory has been developed to analyze the nonlinear 
behavior of a composite beam under given loading by solving finite element equations the formulation is based on the Higher order Shear Deformation Theory (HSDT).

\subsection{LITERATURE REVIEW}

\subsubsection{Large deflections of isotropic beams}

Different frameworks have been developed by several research groups over the years. The numerical results by Mattiasson (1980) involved the evaluation of elliptical integrals to obtain a nonlinear response to large loads.

Bisshopp and Drucker (1945) have studied the large deflection of cantilever beams. They Derive an analytical solution for a cantilever beam subjected to a concentrated vertical load at the free end. The derivation is based on the fundamental Euler-Bernoulli beam which assumes that the curvature is proportional to the bending moment. The results are in agreement with the experimental observations.

Mattiasson (1980) have described a numerical technique for evaluating the elliptic integrals

solutions of some large-deflection beam and frame problems. They present highly-accurate results in tabular form.

Howell and Midha (1995)have developed a simple method for approximating the deflection path of end-loaded, large-deflection cantilever beams. The approximation are accurate to within 0.5 percent of closed form elliptic integral solutions.

\subsubsection{Large deflections of composite beams}

Non-linear analysis of composite beams undergoing large scale deflections are not numerous in the literature.

Sun and Chin (1988) have studied the deflection of asymmetric cross-ply composite laminates and conclude that linear laminate plate theory is in adequate to analyze asymmetric composite laminates with strong extension-bending coupling, and that large-deflection theory should be used even in the small-deflection range. For cylindrical bending problems, they provide a simple procedure by reducing the governing equation to linear differential equation with nonlinear boundary conditions. The von Karman plate-theory is used to analyze composite laminates under in-plane and transverse loadings.

Stemple and Lee (1989) developed a finite element model accounting for the warping effect of composite beams undergoing large deflection or finite rotation. The formulation is used to model combined torsional and extensional behavior of composite helicopter rotor blades. The strain is assumed to vary linearly through the wall thickness. The total Lagrangian description is 
adopted for the formulation and the Newton-Raphson method is applied to solve the nonlinear equilibrium equations resulting from the finite element approximation.

Koo and Kwak(1993)propose a finite element method based on the FSDT for analyzing the deflections of composite frames. Deflections are separately interpolated for bending and shear using cubic and linear functions, respectively. A projected matrix was constructed using equilibrium equation, force and displacement relation. Error due to projection approaches zero with the increase in number of elements. In this method, shear locking has not occurred.

Vo and Lee (2010) analyze geometric nonlinearity of thin walled composite beams with arbitrary lay-ups under various types of loads. The nonlinear finite element equations are solved using the Newton-Raphson method. The formulation is based on FSDT. They develop a displacement-based one-dimensional finite element model that accounts for geometric nonlinearity in the von Karman sense to solve the problem. Numerical results are obtained for a beam under a vertical load.

\subsubsection{Reduction of plate theories to beam}

Chandrasekaran (2000) has studied the behavior of moving laminate composite beams using finite element method based on variational principle. The formulation iscarried outwith theCLPTas well asFSDT. He presents a systematic way to reduce plate theories to beams. Newmark's time integration method is used to find the response of the moving beam. The displacement response is studied for both symmetric and unsymmetric laminates.

Sivaneri and Vennam (2010) have presented a systematic formulation to reduce plate equations to beams. They Study the hygrothermal effects on free-vibration characteristics of rotating composite beams using the finite element analysis based on the variational principle. The formulation is based on FSDT.

Sivaneri and Nagappan (2012) have analyzed the dynamic behavior of axially-moving composite laminated beams based on HSDT. A finite element formulation based on the variational principle is used. They employe a sistematic approach to reduce plate equations to beams. Results are presented in the form of time history of tip deflections. They compare the performance of HSDT model with that of CLPT and FSDT.

Polina and Sivaneri (2014) use a consistent formulation to reduce composite plate equations to beams in the study of vibration attenuation of composite moving beams using active vibration control techniques. A finite element model is developed to reduce the excess vibrations caused by the axial oscillation of the beam. The formulation is based on variational principles. Lagrange multipliers are used to apply the displacement constraints. 
Hanif and Sivaneri (2014) and Sivaneri and Hanif (2014) have studied the effect of hygrothermal conditions and failure analysis, respectively on fiber reinforced composite laminates with moving loads. The formulation is carried out for both CLPT and FSDT. The failure analysis uses the maximum-normal-stress criterion. Different fiber volume fraction with varying fiber orientation of the laminate plies are modeled and studied.

\subsection{Objectives}

The objectives of this research are:

- To analyze the large-deflection of a composite beam using a higher-order shear deformation theory. The formulation of this beam is carried out using the principle of virtual work.

- To determine the nonlinear part of the structural stiffness matrix of a beam made of a composite material.

- To determine the tangential stiffness matrix corresponding to the Newton-Raphson iterative technique.

- To develop a MATLAB code to solve the nonlinear finite element equations for the largedeflection of composite beam using an iterative process.

- To calculate deflection of the composite beam as a function of position under a uniformly distributed load.

\subsection{Organization of thesis}

Chapter two deals with the beam lay-up configuration, introduction to different plate theories and their displacement distributions, and theformulation of the governing equations using principle of virtual work.

Chapter three details the finite element formulation of the linear and nonlinear stiffness matrices, Gaussian integration procedure, and Newton-Raphson iterative method.

Chapter four presents the results in the form deflections as a function of position for composite beams formulated using cylindrical bending and HSDT, respectively. Conclusions of the present work and recommendations for future work are also included. 


\section{THEORETICAL FORMULATION}

\subsection{Introduction}

Composite materials have special/significant properties such as high strength to weight ratio and resistance to wear and corrosion. These advantages drive the usage of composite materials over conventional materials. Composite beams are widely used as structural members. These are subjected to axial, transverse and the formulation of large-deflection analysis of a composite beam is described in this chapter along with a systematic reduction of thecomposite plate theory to a beam.

\subsection{Lay-up configuration}

There are symmetric and unsymmetric lay-ups. A symmetric laminate is one that has the same number of layers with the same orientation and thickness located symmetrically about the mid-plane; otherwise it is unsymmetric. Figure 2.1 shows the sequence of a lamina stacking and the naming convention of a composite laminate. The total height of the laminate is $h$, which has $\mathrm{n}$ layers. The mid-plane is located halfway through the thickness of the plate. $K$ is the lamina number counting from the bottom up and $z_{k}$ is the coordinate of the top surface of the $k^{\text {th }}$ lamina.

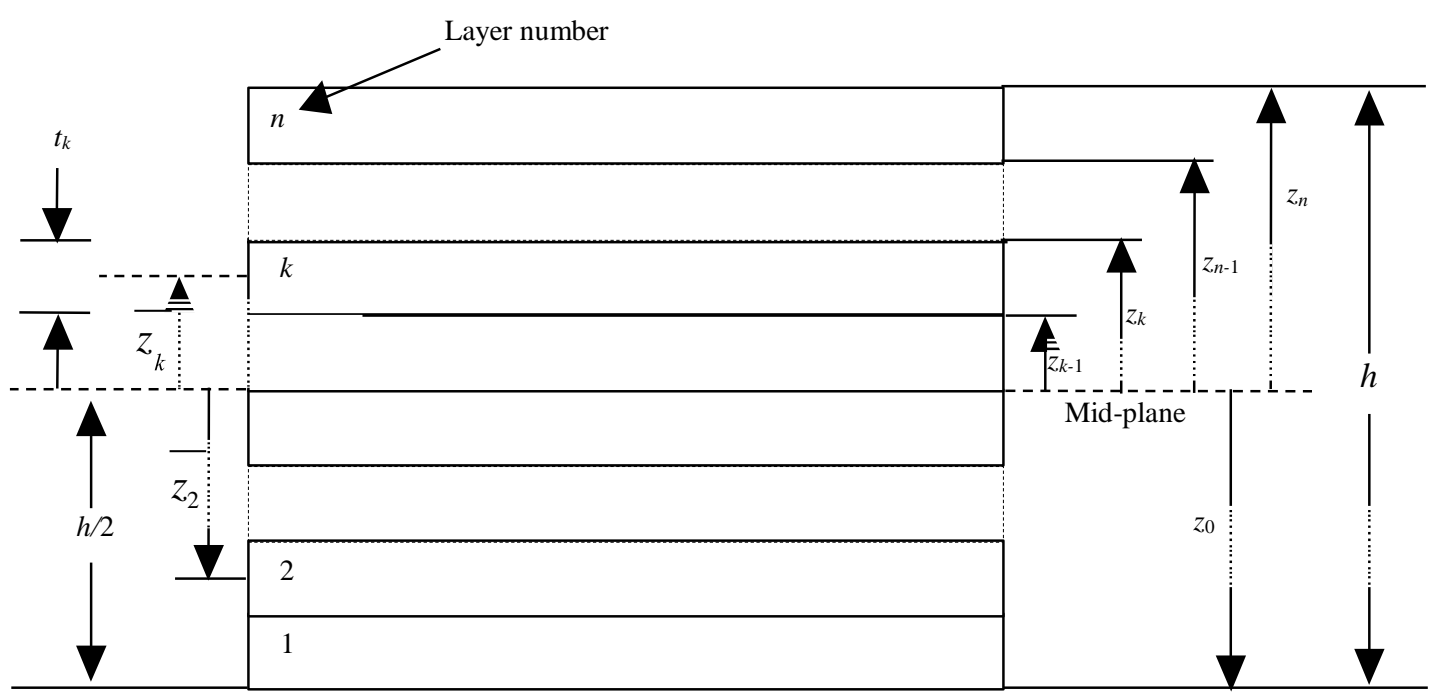

Fig. 2.1 Composite lay-up configuration 


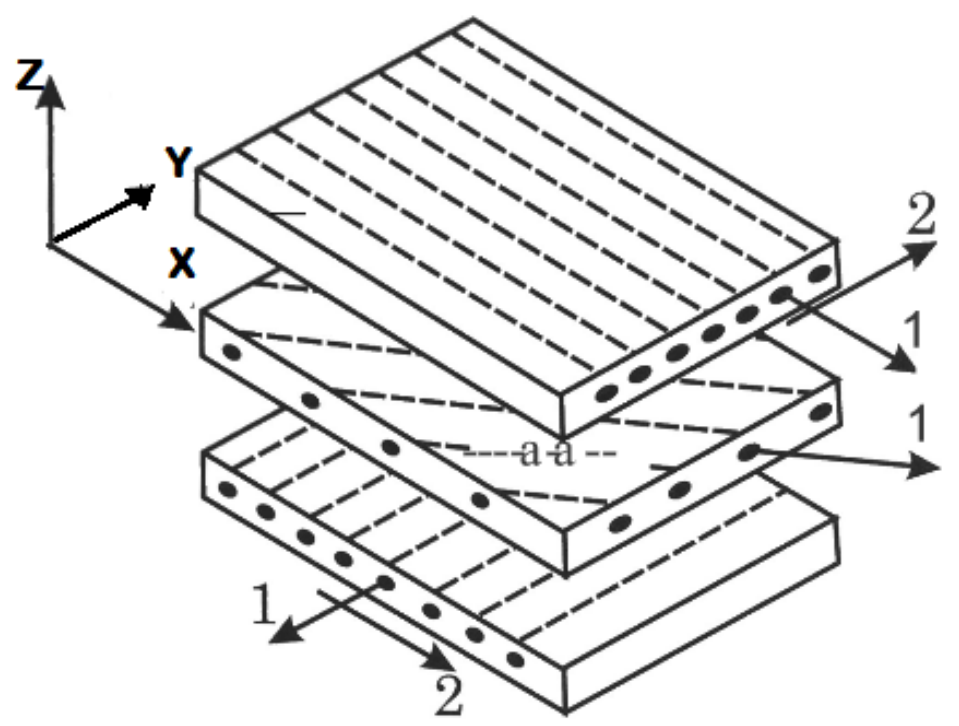

Fig. 2.2 Assembly of three laminae into a laminate [Barbero (1998)]

\subsection{Force and Moments Resultants}

Figure 2.3 shows the mid-plane of the plate on which positive force and moment resultants acting are represented. $N_{x}, N_{y}$ and $N_{x y}$ are the in-plane force resultants acting along $x$ and $y$ directions. $M_{x}, M_{y}$ and $M_{x y}$ are the moment resultants.

(a)

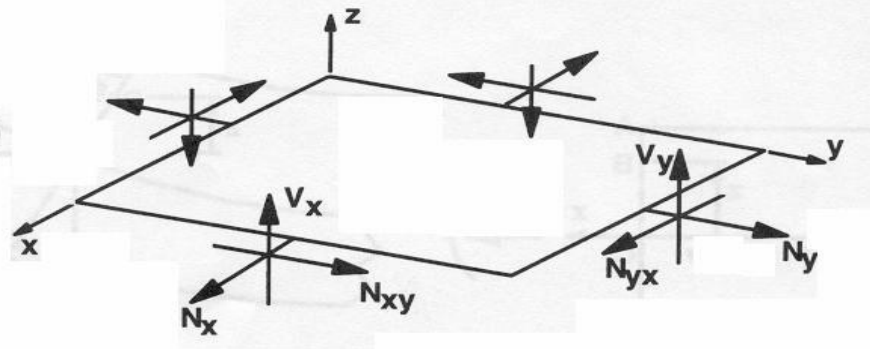

(b)

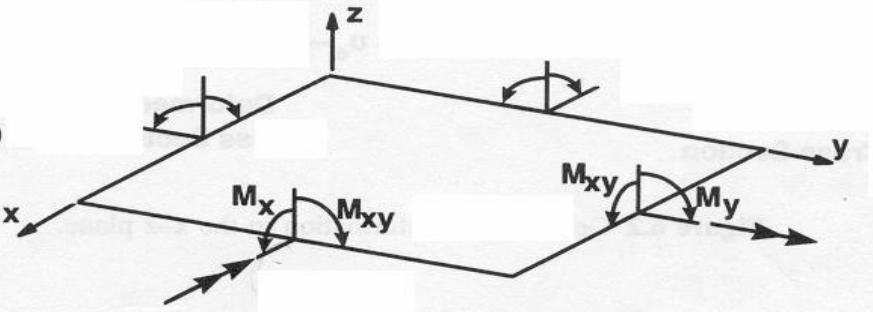

Fig. 2.3 Force and moments resultants on a flat plate [Barbero(1998)] 


\subsection{Plate theories}

Plate theories describe the kinematic behavior of plate elements. Composite laminates are generally treated as plate elements due to the fact that they have larger planar dimensions when compared to the thickness. The most commonly used plate theories are the Classical Laminate Plate Theory (CLPT), First-order Shear Deformation Theory (FSDT), and the Higherorder Shear Deformation Theory (HSDT). The HSDT is employed in this research. The Classical laminate plate theory for composite laminates is an extension of the classical plate theory of isotropic materials. Kirchoff's hypotheses are used in the derivation of the plate stiffness and compliance equations. The assumptions, as stated by Reddy (1997), for CLPT are:

1. Straight lines perpendicular to the mid-surface (transverse normals) before deformation remain straight after deformation.

2. The transverse normals do not experience elongation. $(\varepsilon z z=0)$

3. The transverse normals rotate such that they remain perpendicular to the midsurface after deformation. $(\varepsilon x z=0$ and $\varepsilon y z=0)$

In addition to Kirchoff's hypothesis, the following assumptions are also used:

4. The layers are perfectly bonded together.

5. The material of each layer is linearly elastic and has two planes of material symmetry (i.e., orthotropic).

6. Each layer is of uniform thickness.

7. The strains and displacements are small.

8. The transverse shear stresses on the top and bottom surfaces of the laminate are zero.

From Nagappan (2004), Composites have very low transverse shear modulus compared to their on-axis modulus. In the case of CLPT, the effects of transverse shear are neglected since transverse shear strains ( $\gamma \mathrm{xz}$ and $\mathrm{pyz}$ ) are assumed to be zero. This may make the CLPT inadequate for the dynamic response even for a beam with a high slenderness ratio. To consider the effect of transverse shear, an FSDT can be used. The FSDT uses the same assumptions as in CLPT except for the third Kirchoff's hypothesis. In FSDT the transverse normal is assumed to be straight but not perpendicular to the mid-surface after deformation and therefore transverse shear strains are not zero. First order shear deformation theory uses a shear correction factor [Cowper (1996) ,Vlachoutsis (1992)] to correct the shear strain energy but the zero transverse shear conditions at the top and bottom surfaces are not satisfied.ToavoidtheshearcorrectionfactorandtorepresentthekinematicsbetterthanFSDT, higherordersheardeformationtheoriescanbeused [Lo, Christensen and Wu (1977); Levinson (1981); Reddy(1984)]. The third order theory is also based on the same assumptions as that of 
FSDT, except that the assumption on the straightness of the transverse normal after deformation is relaxed. The transverse normal is no longer inextensible, making the deformations as a function of the thickness coordinate $z$.

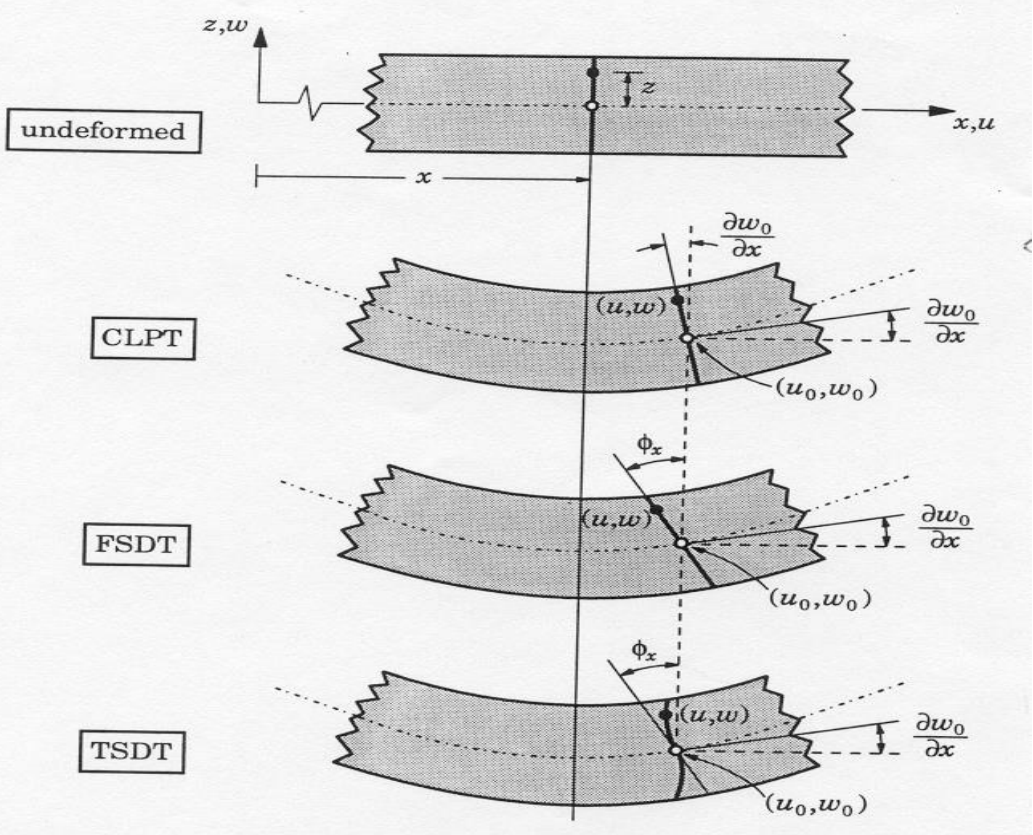

Fig2.4 Deformationof transversenormalforCLPT,FSDTandHSDT[Reddy(1997)]

In HSDT, the displacement field $(u, v, w)$ in the $(x, y, z)$ directions, respectively, can be expressed as [Reddy 1997]:

$$
\begin{gathered}
u(x, y, z, t)=u_{0}(x, y, t)+z \phi_{x}(x, y, t)-c_{1} z^{3}\left(\phi_{x}+c_{0} \frac{\partial w}{\partial x}\right) \\
v(x, y, z, t)=v_{0}(x, y, t)+z \phi_{y}(x, y, t)-c_{1} z^{3}\left(\phi_{y}+c_{0} \frac{\partial w}{\partial y}\right) \\
w(x, y, z, t)=w(x, y, t)=w_{b}(x, y, t)+w_{s}(x, y, t)
\end{gathered}
$$

where $u_{0}$ and $v_{0}$ are the in-plane displacements at the mid-plane and $\phi_{x}$ and $\phi_{y}$ are the rotations of a transverse normal about the $y$ and $x$ axes respectively. The bending deformation $w$ consists of pure bending component $w_{b}$ and a shear component $w_{s}$. In Eq. (2.1) $c_{0}$ is assumed to be unity while $c_{1}=0$ for FSDT and $c_{1}=\frac{4}{3 h^{2}}$ for HSDT.

\subsection{Principle of Virtual Work}

The word virtual means imaginary. A virtual displacement is arbitrary but small, conforms to the kinematic constraints and does not alter the applied loads. Virtual work is done by real load on 
a virtual displacement. The principle of Virtual work states that for a system in static equilibrium, the total virtual work done is zero. Mathematically, the principle of virtual work is

$$
\begin{gathered}
\delta W \equiv 0 \\
=>\delta W_{e}+\delta W_{i}=0
\end{gathered}
$$

where, $\delta W_{e}$ is the external virtual work and $\delta W_{i}$ is the internal virtual work.

Let $Q$ be a generalized force on a system resulting in a corresponding generalized displacement $q$.

External work is defined mathematically as follows

$$
W_{e}=\int_{0}^{q} Q d q
$$

Thus, the external virtual work is

$$
\delta W_{e}=Q \delta q
$$

Internal Virtual Work can be obtained from virtual strain energy as follows

$$
\delta U=\iiint_{V} \delta U_{0} d V
$$

where $U_{0}$ is the stain energy density.

$$
\delta W_{i}=-\delta \mathrm{U}
$$

Thus, substituting Eq. 2.6 and Eq. 2.4 $\left(\delta W_{i}\right.$ and $\left.\delta W_{e}\right)$ in Principle of Virtual Work Eq. 2.2, we get

$$
\delta W_{e}=\delta \mathrm{U}
$$

Generally, external work is represented with symbol ' $W$ '

Thus, Principle of Virtual Work is

$$
\delta U=\delta \mathrm{W}
$$




\subsubsection{Kinematic Equations of composite plate}

The nonlinear kinematic equations for moderate rotations are given by [Reddy (1997)],

$\varepsilon_{x}=\frac{\partial \mathrm{u}}{\partial \mathrm{x}}+\frac{1}{2}\left(\frac{\partial \mathrm{w}}{\partial \mathrm{x}}\right)^{2}$

$\varepsilon_{y}=\frac{\partial \mathrm{v}}{\partial \mathrm{y}}+\frac{1}{2}\left(\frac{\partial \mathrm{w}}{\partial \mathrm{y}}\right)^{2}$

$\gamma_{\mathrm{xy}}=\left(\frac{\partial \mathrm{u}}{\partial \mathrm{y}}+\frac{\partial \mathrm{v}}{\partial \mathrm{x}}+\frac{\partial \mathrm{w}}{\partial \mathrm{x}} \frac{\partial \mathrm{w}}{\partial \mathrm{y}}\right)$

$\gamma_{\mathrm{yz}}=\left(\frac{\partial \mathrm{v}}{\partial \mathrm{z}}+\frac{\partial \mathrm{w}}{\partial \mathrm{y}}\right)$

$\gamma_{\mathrm{xz}}=\left(\frac{\partial \mathrm{u}}{\partial \mathrm{z}}+\frac{\partial \mathrm{w}}{\partial \mathrm{x}}\right)$

Substituting Eq. (2.9) into Eq. (2.1) we get,

$\varepsilon_{x}=\frac{\partial u_{0}}{\partial x}+\frac{1}{2}\left(\frac{\partial w}{\partial x}\right)^{2}+z \frac{\partial \phi_{x}}{\partial x}-c_{1} z^{3}\left(\frac{\partial \phi_{x}}{\partial x}+\frac{\partial^{2} w}{\partial x^{2}}\right)$

$\varepsilon_{y}=\frac{\partial v_{0}}{\partial y}+\frac{1}{2}\left(\frac{\partial w}{\partial y}\right)^{2}+z \frac{\partial \phi_{y}}{\partial y}-c_{1} z^{3}\left(\frac{\partial \phi_{y}}{\partial y}+\frac{\partial^{2} w}{\partial y^{2}}\right)$

$\gamma_{x y}=\frac{\partial u_{0}}{\partial y}+\frac{\partial v_{0}}{\partial x}+\frac{\partial w}{\partial x} \frac{\partial w}{\partial y}+z\left(\frac{\partial \emptyset_{x}}{\partial y}+\frac{\partial \emptyset_{y}}{\partial x}\right)-c_{1} z^{3}\left(\frac{\partial \emptyset_{x}}{\partial y}+\frac{\partial \emptyset_{y}}{\partial x}+2 \frac{\partial^{2} w}{\partial x \partial y}\right)$

$\gamma_{y z}=\phi_{y}+\frac{\partial w}{\partial y}-3 c_{1} z^{2}\left(\phi_{y}+\frac{\partial w}{\partial y}\right)$

$\gamma_{z x}=\phi_{x}+\frac{\partial w}{\partial x}-3 c_{1} z^{2}\left(\phi_{x}+\frac{\partial w}{\partial x}\right)$

The transverse normal rotations at the mid-plane, $\phi_{x}$ and $\phi_{y}$ can be written as,

$$
\begin{aligned}
& \phi_{x}=\frac{\partial u_{0}}{\partial z}=-\frac{\partial w_{b}}{\partial x} \\
& \phi_{y}=\frac{\partial v_{0}}{\partial z}=-\frac{\partial w_{b}}{\partial y}
\end{aligned}
$$

Then $\phi_{x}+\frac{\partial w}{\partial x}=-\frac{\partial w_{b}}{\partial x}+\frac{\partial w_{b}}{\partial x}+\frac{\partial w_{s}}{\partial x}=\frac{\partial w_{s}}{\partial x}$ 
Similarly, $\phi_{y}+\frac{\partial w}{\partial y}=\frac{\partial w_{s}}{\partial y}$

The strains in Eq. (2.10) can also be written as,

$$
\begin{gathered}
\varepsilon_{x}=\varepsilon_{x}^{(0)}+z \varepsilon_{x}^{(1)}+z^{3} \varepsilon_{x}^{(3)} \\
\varepsilon_{y}=\varepsilon_{y}^{(0)}+z \varepsilon_{y}^{(1)}+z^{3} \varepsilon_{y}^{(3)} \\
\gamma_{x y}=\gamma_{x y}^{(0)}+z \gamma_{x y}^{(1)}+z^{3} \gamma_{x y}^{(3)} \\
\gamma_{y z}=\gamma_{y z}^{(0)}+z^{2} \gamma_{y z}^{(2)} \\
\gamma_{z x}=\gamma_{z x}^{(0)}+z^{2} \gamma_{z x}^{(2)}
\end{gathered}
$$

Where,

$$
\begin{aligned}
& \varepsilon_{x}^{(0)}=\frac{\partial u_{0}}{\partial x}+\frac{1}{2}\left(\frac{\partial w_{b}}{\partial x}\right)^{2}+\frac{1}{2}\left(\frac{\partial w_{s}}{\partial x}\right)^{2} \\
& \varepsilon_{x}^{(1)}=-\frac{\partial^{2} w_{b}}{\partial x^{2}} \\
& \varepsilon_{x}^{(3)}=-c_{1} \frac{\partial^{2} w_{s}}{\partial x^{2}} \\
& \varepsilon_{y}^{(0)}=\frac{\partial v_{0}}{\partial y}+\frac{1}{2}\left(\frac{\partial w_{b}}{\partial y}\right)^{2}+\frac{1}{2}\left(\frac{\partial w_{s}}{\partial y}\right)^{2} \\
& \varepsilon_{y}^{(1)}=-\frac{\partial^{2} w_{b}}{\partial y^{2}} \\
& \varepsilon_{y}^{(3)}=-c_{1} \frac{\partial^{2} w_{s}}{\partial y^{2}} \\
& \gamma_{x y}^{(0)}=\frac{\partial u_{0}}{\partial y}+\frac{\partial v_{0}}{\partial x}+\left(\frac{\partial w_{b}}{\partial x}+\frac{\partial w_{s}}{\partial x}\right)\left(\frac{\partial w_{b}}{\partial y}+\frac{\partial w_{s}}{\partial y}\right)
\end{aligned}
$$

The term $\left(\frac{\partial w_{b}}{\partial x}+\frac{\partial w_{s}}{\partial x}\right)\left(\frac{\partial w_{b}}{\partial y}+\frac{\partial w_{s}}{\partial y}\right)$ is the above expression is a nonlinear term.

$$
\begin{aligned}
& \gamma_{x y}^{(1)}=-2 \frac{\partial^{2} w_{b}}{\partial x \partial y} \\
& \gamma_{x y}^{(3)}=-2 c_{1} \frac{\partial^{2} w_{s}}{\partial x \partial y}
\end{aligned}
$$




$$
\begin{aligned}
& \gamma_{y z}^{(0)}=\frac{\partial w_{s}}{\partial y} \\
& \gamma_{y z}^{(2)}=-3 c_{1} \frac{\partial w_{s}}{\partial y} \\
& \gamma_{y z}^{(0)}=\frac{\partial w_{s}}{\partial y} \\
& \gamma_{x z}^{(2)}=-3 c_{1} \frac{\partial w_{s}}{\partial x}
\end{aligned}
$$

\subsubsection{Virtual Strain Energy for a Plate}

The total virtual strain energy for a plate is given as,

$\delta \mathrm{U}=\iiint_{V}\left[\sigma_{x} \delta \varepsilon_{x}+\sigma_{y} \delta \varepsilon_{y}+\tau_{x y} \delta \gamma_{x y}+\tau_{y z} \delta \gamma_{y z}+\tau_{x z} \delta \gamma_{x z}\right] d V$

where, $\delta \varepsilon_{x}, \delta \varepsilon_{y}, \delta \gamma_{x y}, \delta \gamma_{y z}$, and $\delta \gamma_{x z}$ are thevirtual strains and $\mathrm{V}$ is the volume of the plate. Separating the volume integral into an integral over the thickness coordinate $Z$ and an area integral in the $x, y$ directions we get,

$\delta U=\iint_{A} \int_{-\frac{h}{2}}^{\frac{h}{2}}\left[\sigma_{x} \delta \varepsilon_{x}+\sigma_{y} \delta \varepsilon_{y}+\tau_{x y} \delta \gamma_{x y}+\tau_{y z} \delta \gamma_{y z}+\tau_{x z} \delta \gamma_{x z}\right] d A d z$

Defining Stress resultants as follows

$$
\begin{aligned}
& \left(N_{x}, N_{y}, N_{x y}\right)=\int_{-h / 2}^{-h / 2}\left(\sigma_{x}, \sigma_{y}, \tau_{x y}\right) d z \\
& \left(M_{x}, M_{y}, M_{x y}\right)=\int_{-h / 2}^{-h / 2}\left(\sigma_{x}, \sigma_{y}, \tau_{x y}\right) z d z \\
& \left(P_{x}, P_{y}, P_{x y}\right)=\int_{-h / 2}^{-h / 2}\left(\sigma_{x}, \sigma_{y}, \tau_{x y}\right) z^{3} d z \\
& \left(Q_{x}, Q_{y}\right)=\int_{-h / 2}^{-h / 2}\left(\tau_{x y}, \tau_{y z}\right) d z \\
& \left(R_{x}, R_{y}\right)=\int_{-h / 2}^{-h / 2}\left(\tau_{x y}, \tau_{y z}\right) z^{2} d z
\end{aligned}
$$


The quantities $\left(N_{x}, N_{y}, N_{x y}\right)$ are the in-plane force resultants, $\left(M_{x}, M_{y}, M_{x y}\right)$ are the moment resultants, $\left(Q_{x}, Q_{y}\right)$ are the transverse force resultants and $\left(P_{x}, P_{y}, P_{x y}, R_{x}, R_{y}\right)$ are the higher order stress resultants. Then the strain energy equation of the plate simplifies to:

$$
\begin{aligned}
& \delta \mathrm{U}=\iint_{A}\left[N_{x} \delta \varepsilon_{x}^{(0)}+M_{x} \delta \varepsilon_{x}^{(1)}+P_{x} \delta \varepsilon_{x}^{(3)}+N_{y} \delta \varepsilon_{y}^{(0)}+M_{y} \delta \varepsilon_{y}^{(1)}+P_{y} \delta \varepsilon_{y}^{(3)}+N_{x y} \delta \gamma_{x y}^{(0)}+\right. \\
& \left.M_{x y} \delta \gamma_{x y}^{(1)}+P_{x y} \delta \gamma_{x y}^{(3)}+Q_{x} \delta \gamma_{z x}^{(0)}+R_{x} \delta \gamma_{z x}^{(2)}+Q_{y} \delta \gamma_{y z}^{(0)}+R_{y} \delta \gamma_{y z}^{(2)}\right] d A
\end{aligned}
$$

\subsubsection{Constitutive Equations}

The relation between the stress resultants and strains are given by:

$$
\begin{aligned}
& \left\{\begin{array}{l}
\{N\} \\
\{M\} \\
\{P\}
\end{array}\right\}=\left[\begin{array}{lll}
{[A]} & {[B]} & {[E]} \\
{[B]} & {[D]} & {[F]} \\
{[E]} & {[F]} & {[H]}
\end{array}\right]\left\{\begin{array}{l}
\left\{\varepsilon^{(0)}\right\} \\
\left\{\varepsilon^{(1)}\right\} \\
\left\{\varepsilon^{(3)}\right\}
\end{array}\right\} \\
& \left\{\begin{array}{l}
\{Q\} \\
\{R\}
\end{array}\right\}=\left[\begin{array}{ll}
{[A]} & {[D]} \\
{[D]} & {[F]}
\end{array}\right]\left\{\begin{array}{l}
\gamma^{(0)} \\
\gamma^{(2)}
\end{array}\right\}
\end{aligned}
$$

Vectors $\{N\}$ and $\{M\}$ represent the force and moment resultants. Vector $\{Q\}$ denote the transverse force resultants, while vectors $\{P\}$ and $\{R\}$ represent the higher-order stress resultants. Matrices $[A],[B]$ and $[D]$ contain the extension stiffness, bending-extension coupling and bending stiffness coefficients while matrices $[E],[F]$ and $[H]$ have higher-order stiffness coefficient terms. The coefficient matrices in Eq. (2.18) are obtained from,

$$
\left(A_{i j}, B_{i j}, D_{i j}, E_{i j}, F_{i j}, H_{i j}\right)=\sum_{k=1}^{n} \int_{z_{k-1}}^{z_{k}} \bar{Q}_{i j}^{(k)}\left(1, z, z^{2}, z^{3}, z^{4}, z^{6}\right) d z
$$

The square matrices in Eq. (2.18) are of order $3 \times 3$ and the stiffness coefficients are defined for $i, j=1,2,6$. The $\bar{Q}_{i j}^{(k)}$ denotes the off-axis material stiffness coefficients of the $k^{\text {th }}$ layer. Matrices in Eq. (2.19) are obtained from,

$$
\left(A_{i j}, D_{i j}, F_{i j}\right)=\sum_{k=1}^{n} \int_{z_{k-1}}^{z_{k}} \bar{Q}_{i j}^{(k)}\left(1, z^{2}, z^{6}\right) d z
$$

where, $[A],[D]$ and $[F]$ are $2 \times 2$ matrices with $i, j=4,5$.

\subsubsection{Reduction of Plate Equations to Beams [Nagappan (2004)]}

For isotropic materials beam theories were developed first since they are much simpler than the corresponding plate theories whereas plate theories were developed first in case of 
composite materials. Chandrasekaran and Sivaneri (2000) studied an efficient way to reduce these plate theories to corresponding beam theories. This process for HSDT is outlined in this section.

For beams, the lateral resultants forces are negligible. Hence, $N_{y}, M_{y}, P_{y}$, are set to zero in Eq. (2.18).Similarly, $Q_{y}$ and $R_{y}$ are set to zero in Eq. (2.19). By rearranging Eq. (2.18) we get,

$\left\{\begin{array}{c}N_{x} \\ N_{x y} \\ M_{x} \\ M_{x y} \\ P_{x} \\ P_{x y} \\ 0 \\ 0 \\ 0\end{array}\right\}=\left[\begin{array}{lllllllll}A_{11} & A_{16} & B_{11} & B_{16} & E_{11} & E_{16} & A_{12} & B_{12} & E_{12} \\ A_{16} & A_{66} & B_{16} & B_{66} & E_{16} & E_{66} & A_{26} & B_{26} & E_{26} \\ B_{11} & B_{16} & D_{11} & D_{16} & F_{11} & F_{16} & B_{12} & D_{12} & F_{12} \\ B_{16} & B_{66} & D_{16} & D_{66} & F_{16} & F_{66} & B_{26} & D_{26} & F_{26} \\ E_{11} & E_{16} & F_{11} & F_{16} & H_{11} & H_{16} & E_{12} & F_{12} & H_{12} \\ E_{16} & E_{66} & F_{16} & F_{66} & H_{16} & H_{66} & E_{26} & F_{26} & H_{26} \\ A_{12} & A_{26} & B_{12} & B_{26} & E_{12} & E_{26} & A_{22} & B_{22} & E_{22} \\ B_{12} & B_{26} & D_{12} & D_{26} & F_{12} & F_{26} & B_{22} & D_{22} & F_{22} \\ E_{12} & E_{26} & F_{12} & F_{26} & H_{12} & H_{26} & E_{22} & F_{22} & H_{22}\end{array}\right]\left\{\begin{array}{c}\varepsilon_{x}^{(0)} \\ \gamma_{x y}^{(0)} \\ \varepsilon_{x}^{(1)} \\ \gamma_{x y}^{(1)} \\ \varepsilon_{x}^{(3)} \\ \gamma_{x y}^{(3)} \\ \varepsilon_{y}^{(0)} \\ \varepsilon_{y}^{(1)} \\ \varepsilon_{y}^{(3)}\end{array}\right\}$

Representing the above matrix as follows

$\left\{\begin{array}{c}\{\bar{N}\} \\ \{0\}\end{array}\right\}=\left[\begin{array}{ll}{\left[T^{11}\right]} & {\left[T^{12}\right]} \\ {\left[T^{21}\right]} & {\left[T^{22}\right]}\end{array}\right]\left\{\begin{array}{c}\{\bar{\varepsilon}\} \\ \left\{\overline{\varepsilon_{y}}\right\}\end{array}\right\}$

It can be observed that

$\left[T^{21}\right]=\left[T^{12}\right]^{T}$

Expanding Eq. (2.23)

$\{\bar{N}\}=\left[T^{11}\right]\{\bar{\varepsilon}\}+\left[T^{12}\right]\left\{\overline{\varepsilon_{y}}\right\}$

$$
\{0\}=\left[T^{21}\right]\{\bar{\varepsilon}\}+\left[T^{22}\right]\left\{\overline{\varepsilon_{y}}\right\}
$$

Omitting $\left\{\overline{\varepsilon_{y}}\right\}$ in Eq. (2.25) we get,

$\{\bar{N}\}=[T]\{\bar{\varepsilon}\}$

where $[T]=\left[\left[T^{11}\right]-\left[T^{12}\right]\left[T^{22}\right]^{-1}\left[T^{21}\right]\right]$

Similarly, Eq. (2.19) can be rearranged and partitioned by setting $Q_{y}=R_{y}=0$, 
$\left\{\begin{array}{c}Q_{x} \\ R_{x} \\ \cdots \\ 0 \\ 0\end{array}\right\}=\left[\begin{array}{ccccc}A_{55} & D_{55} & \vdots & A_{45} & D_{45} \\ D_{55} & F_{55} & \vdots & D_{45} & F_{45} \\ \cdots & \cdots & \vdots & \cdots & \cdots \\ A_{45} & D_{45} & \vdots & A_{44} & D_{44} \\ D_{45} & F_{45} & \vdots & D_{44} & F_{44}\end{array}\right]\left\{\begin{array}{c}\gamma_{x z}^{(0)} \\ \gamma_{x z}^{(2)} \\ \cdots \\ \gamma_{y z}^{(0)} \\ \gamma_{y z}^{(2)}\end{array}\right\}$

Say the notations, $w_{s}^{\prime}=\frac{\partial w_{s}}{\partial x}$ and $w_{s}^{y}=\frac{\partial w_{s}}{\partial y}$ in Eq. (2.13), the strain vector in Eq. (2.28) becomes,

$\left\lfloor\gamma_{x z}^{(0)} \gamma_{x z}^{(2)} \gamma_{y z}^{(2)} \gamma_{y z}^{(2)}\right\rfloor=\left\lfloor\begin{array}{lll}w_{s}^{\prime} & -3 c_{1} w_{s}^{\prime} w_{s}^{y} & -3 c_{1} w_{s}^{y}\end{array}\right\rfloor$

Define

$D_{i j}^{*}=A_{i j}-6 c_{1} D_{i j}+9 c_{1}^{2} F_{i j}$

$Q_{x}^{*}=Q_{x}-3 c_{1} R_{x}$

$Q_{y}^{*}=Q_{y}-3 c_{1} R_{y}$

Substituting Eq. (2.30) into Eq. (2.28) we get,

$\left\{\begin{array}{c}Q_{y}^{*} \\ Q_{x}^{*}\end{array}\right\}=K\left[\begin{array}{ll}D_{44}^{*} & D_{45}^{*} \\ D_{45}^{*} & D_{55}^{*}\end{array}\right]\left\{\begin{array}{c}\left\{w_{s}^{y}\right\} \\ \left\{w_{s}^{\prime}\right\}\end{array}\right\}$

A factor K known as shear correction factor in the Eq. (2.31) is introduced even though HSDT does not require. This is done to obtain FSDT results from the HSDT formulation by setting $c_{1}=0$ and $\mathrm{K}=5 / 6$. For HSDT case $\mathrm{K}$ will be one.

For a beam, $Q_{y}^{*}$ is set to 0 .Thus, solving Eq. (2.31) we get,

$Q_{x}^{*}=\mathrm{K} D_{55}^{* *} w_{s}^{\prime}$

Where $D_{55}^{* *}=D_{55}^{*}-\frac{D_{45}^{* 2}}{D_{44}^{*}}$

\subsubsection{Virtual Strain Energy of a Composite Beam}

To obtain strain energy for beam, employ the systematic way discussed above i.e $N_{y}=M_{y}=$ $P_{y}=Q_{y}=R_{y}=0$. For a rectangular beam of width $b$ and length $L$, the area integral in Eq. (2.17) is changed to a line integral along $x$ and further substituting kinematic Eqs. (2.13) and (2.14) in Eq. (2.17) and following notations are used 


$$
\begin{aligned}
& ()^{\prime}=\frac{\partial()}{\partial x} \\
& ()^{\prime}=\frac{\partial()}{\partial y} \\
& ()^{\prime \prime}=\frac{\partial^{2}()}{\partial x^{2}} \\
& ()^{\prime y}=\frac{\partial^{2}()}{\partial x \partial y} \\
& \gamma_{0}=\frac{\partial u_{0}}{\partial y}+\frac{\partial v_{0}}{\partial x}
\end{aligned}
$$

Then $\delta U$ becomes,

$$
\begin{aligned}
& \delta U=b \int_{0}^{l}\left[N_{x}\left(\delta u_{0}^{\prime}+w_{b}^{\prime} \delta w_{b}^{\prime}+w_{s}^{\prime} \delta w_{s}^{\prime}\right)-M_{x} \delta w_{b}^{\prime \prime}-P_{x} c_{1} \delta w_{s}^{\prime \prime}+N_{x y}\left(\delta \gamma_{0}+\left(\delta w_{b}^{\prime}+\right.\right.\right. \\
& \left.\left.\left.\delta w_{s}^{\prime}\right)\left(w_{b}^{y}+w_{s}^{y}\right)+\left(w_{b}^{\prime}+w_{s}^{\prime}\right)\left(\delta w_{b}^{y}+\delta w_{s}^{y}\right)\right)-2 M_{x y} \delta w_{b}^{\prime y}-2 P_{x y} c_{1} \delta w_{s}^{\prime y}+Q_{x}^{*} \delta w_{s}^{\prime}\right] d x(2.35
\end{aligned}
$$

Where,

$$
N_{x}\left(\delta u_{0}^{\prime}+w_{b}^{\prime} \delta w_{b}^{\prime}+w_{s}^{\prime} \delta w_{s}^{\prime}\right)=N_{x} \delta u_{0}^{\prime}+N_{x} w_{b}^{\prime} \delta w_{b}^{\prime}+N_{x} w_{s}^{\prime} \delta w_{s}^{\prime}
$$

From constitutive equation Eq. (2.22), substituting $N_{x}, M_{x}, P_{x}, N_{x y}, M_{x y}$ and $P_{x y}$ in the above Eq.

(2.36) gives,

$$
\begin{aligned}
N_{x}\left(\delta u_{0}^{\prime}+w_{b}^{\prime} \delta\right. & \left.w_{b}^{\prime}+w_{s}^{\prime} \delta w_{s}^{\prime}\right) \\
& =\left(T_{11} u_{0}^{\prime}+T_{12} \gamma_{0}-T_{13} w_{b}^{\prime \prime}-2 T_{14} w_{b}^{\prime y}-c_{1} T_{15} w_{s}^{\prime \prime}-2 c_{1} T_{16} w_{s}^{\prime y}\right) \delta u_{0}^{\prime} \\
& +N_{x} w_{b}^{\prime} \delta w_{b}^{\prime}+N_{x} w_{s}^{\prime} \delta w_{s}^{\prime} \\
& +\left(\frac{T_{11}}{2} w_{b}^{\prime} \delta u_{0}^{\prime} w_{b}^{\prime}+\frac{T_{11}}{2} w_{s}^{\prime} \delta u_{0}^{\prime} w_{s}^{\prime}\right. \\
& \left.+T_{12}\left(w_{b}^{\prime} w_{b}^{y} \delta u_{0}^{\prime}+w_{b}^{\prime} w_{s}^{y} \delta u_{0}^{\prime}+w_{s}^{\prime} w_{b}^{y} \delta u_{0}^{\prime}+w_{s}^{\prime} w_{s}^{y} \delta u_{0}^{\prime}\right)\right) \\
-M_{x} \delta w_{b}^{\prime \prime}=- & \left(T_{31} u_{0}^{\prime}+T_{32} \gamma_{0}-T_{33} w_{b}^{\prime \prime}-2 T_{34} w_{b}^{\prime y}-c_{1} T_{35} w_{s}^{\prime \prime}-2 c_{1} T_{36} w_{s}^{\prime y}\right) \delta w_{b}^{\prime \prime} \\
& -\left(\frac{T_{31}}{2} w_{b}^{\prime} \delta w_{b}^{\prime \prime} w_{b}^{\prime}+\frac{T_{31}}{2} w_{s}^{\prime} \delta w_{b}^{\prime \prime} w_{s}^{\prime}\right. \\
& \left.+T_{32}\left(w_{b}^{\prime} w_{b}^{y} \delta w_{b}^{\prime \prime}+w_{b}^{\prime} w_{s}^{y} \delta w_{b}^{\prime \prime}+w_{s}^{\prime} w_{b}^{y} \delta w_{b}^{\prime \prime}+w_{s}^{\prime} w_{s}^{y} \delta w_{b}^{\prime \prime}\right)\right)
\end{aligned}
$$




$$
\begin{aligned}
& -P_{x} c_{1} \delta w_{s}^{\prime \prime}=-c_{1}\left(T_{51} u_{0}^{\prime}+T_{52} \gamma_{0}-T_{53} w_{b}^{\prime \prime}-2 T_{54} w_{b}^{\prime y}-c_{1} T_{55} w_{s}^{\prime \prime}-2 c_{1} T_{56} w_{s}^{\prime y}\right) \delta w_{s}^{\prime \prime} \\
& -c_{1}\left(\frac{T_{51}}{2} w_{b}^{\prime} \delta w_{s}^{\prime \prime} w_{b}^{\prime}+\frac{T_{51}}{2} w_{s}^{\prime} \delta w_{s}^{\prime \prime} w_{s}^{\prime}\right. \\
& \left.+T_{52}\left(w_{b}^{\prime} w_{b}^{y} \delta w_{s}^{\prime \prime}+w_{b}^{\prime} w_{s}^{y} \delta w_{s}^{\prime \prime}+w_{s}^{\prime} w_{b}^{y} \delta w_{s}^{\prime \prime}+w_{s}^{\prime} w_{s}^{y} \delta w_{s}^{\prime \prime}\right)\right) \\
& N_{x y}\left(\delta \gamma_{0}+\left(\delta w_{b}^{\prime}+\delta w_{s}^{\prime}\right)\left(w_{b}^{y}+w_{s}^{y}\right)+\left(w_{b}^{\prime}+w_{s}^{\prime}\right)\left(\delta w_{b}^{y}+\delta w_{s}^{y}\right)\right) \\
& =N_{x y} \delta \gamma_{0}+N_{x y}\left(\left(w_{b}^{\prime}+w_{s}^{\prime}\right) \delta w_{b}^{y}\right)+N_{x y}\left(\left(w_{b}^{\prime}+w_{s}^{\prime}\right) \delta w_{s}^{y}\right) \\
& +N_{x y}\left(\left(w_{b}^{y}+w_{s}^{y}\right) \delta w_{b}^{\prime}\right)+N_{x y}\left(\left(w_{b}^{y}+w_{s}^{y}\right) \delta w_{s}^{\prime}\right) \\
& =\left(T_{21} u_{0}^{\prime}+T_{22} \gamma_{0}-T_{23} w_{b}^{\prime \prime}-2 T_{24} w_{b}^{\prime y}-c_{1} T_{25} w_{s}^{\prime \prime}-2 c_{1} T_{26} w_{s}^{\prime y}\right) \delta \gamma_{0} \\
& +\left(\frac{T_{21}}{2} w_{b}^{\prime} \delta \gamma_{0} w_{b}^{\prime}+\frac{T_{21}}{2} w_{s}^{\prime} \delta \gamma_{0} w_{s}^{\prime}\right. \\
& \left.+T_{22}\left(w_{b}^{\prime} w_{b}^{y} \delta \gamma_{0}+w_{b}^{\prime} w_{s}^{y} \delta \gamma_{0}+w_{s}^{\prime} w_{b}^{y} \delta \gamma_{0}+w_{s}^{\prime} w_{s}^{y} \delta \gamma_{0}\right)\right) \\
& +N_{x y}\left(\left(w_{b}^{\prime}+w_{s}^{\prime}\right) \delta w_{b}^{y}\right)+N_{x y}\left(\left(w_{b}^{\prime}+w_{s}^{\prime}\right) \delta w_{s}^{y}\right)+N_{x y}\left(\left(w_{b}^{y}+w_{s}^{y}\right) \delta w_{b}^{\prime}\right) \\
& +N_{x y}\left(\left(w_{b}^{y}+w_{s}^{y}\right) \delta w_{s}^{\prime}\right) \\
& -2 M_{x y} \delta w_{b}^{\prime y}=-2\left(T_{41} u_{0}^{\prime}+T_{42} \gamma_{0}-T_{43} w_{b}^{\prime \prime}-2 T_{44} w_{b}^{\prime y}-c_{1} T_{45} w_{s}^{\prime \prime}-2 c_{1} T_{46} w_{s}^{\prime y}\right) \delta w_{b}^{\prime y} \\
& -2\left(\frac{T_{41}}{2} w_{b}^{\prime} \delta w_{b}^{\prime y} w_{b}^{\prime}+\frac{T_{41}}{2} w_{s}^{\prime} \delta w_{b}^{\prime y} w_{s}^{\prime}\right. \\
& \left.+T_{42}\left(w_{b}^{\prime} w_{b}^{y} \delta w_{b}^{\prime y}+w_{b}^{\prime} w_{s}^{y} \delta w_{b}^{\prime y}+w_{s}^{\prime} w_{b}^{y} \delta w_{b}^{\prime y}+w_{s}^{\prime} w_{s}^{y} \delta w_{b}^{\prime y}\right)\right) \\
& -2 P_{x y} c_{1} \delta w_{s}^{\prime y}=-2 c_{1}\left(T_{61} u_{0}^{\prime}+T_{62} \gamma_{0}-T_{63} w_{b}^{\prime \prime}-2 T_{64} w_{b}^{\prime y}-c_{1} T_{65} w_{s}^{\prime \prime}-2 c_{1} T_{66} w_{s}^{\prime y}\right) \delta w_{s}^{\prime y}- \\
& 2 c_{1}\left(\frac{T_{61}}{2} w_{b}^{\prime} \delta w_{s}^{\prime y} w_{b}^{\prime}+\frac{T_{61}}{2} w_{s}^{\prime} \delta w_{s}^{\prime y} w_{s}^{\prime}+T_{62}\left(w_{b}^{\prime} w_{b}^{y} \delta w_{s}^{\prime y}+w_{b}^{\prime} w_{s}^{y} \delta w_{s}^{\prime y}+\right.\right. \\
& \left.\left.w_{s}^{\prime} w_{b}^{y} \delta w_{s}^{\prime y}+w_{s}^{\prime} w_{s}^{y} \delta w_{s}^{\prime y}\right)\right)
\end{aligned}
$$

\subsubsection{Large Deflection Cylindrical Bending of Composite Plates}

Consider a laminated plate as show in figure 2.5. Suppose the plate is long in the $x$-direction and has finite dimensions along the $y$ - direction and subjected to transverse load $P_{z}(x, y)$ which is uniform at any section parallel to the $y$ axis. In such a case plate bends into a cylindrical surface and is similar to beam bending.

The kinematic equations are as follows 


$$
\begin{aligned}
& \varepsilon_{x}=u^{\prime}+\frac{1}{2}\left(w^{\prime}\right)^{2}-z w^{\prime \prime} \\
& \varepsilon_{y}=0 \\
& \gamma_{x y}=0
\end{aligned}
$$

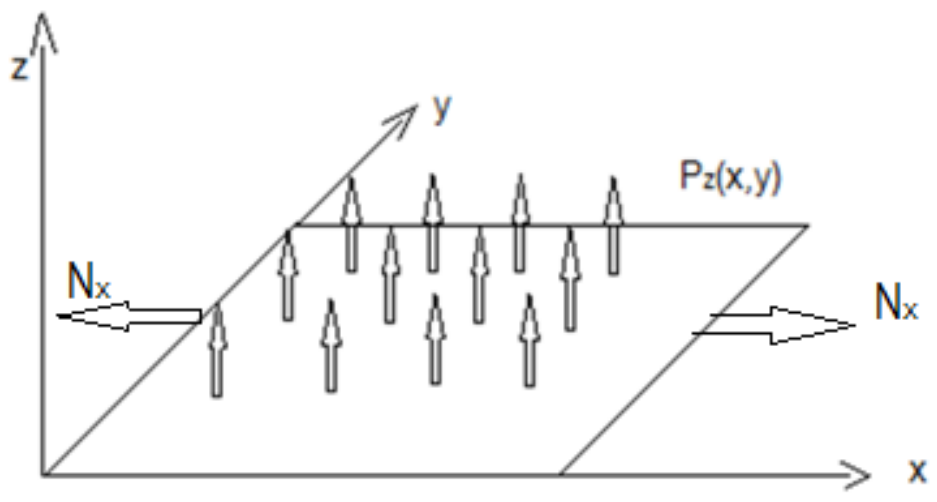

Fig. 2.5 Transverse load $P_{z}(x, y)$ on a laminated plate

The constitutive equations are

$\left\{\begin{array}{l}\sigma_{x} \\ \sigma_{y} \\ \sigma_{z}\end{array}\right\}_{K}=[\bar{Q}]_{K}\left\{\begin{array}{l}\varepsilon_{x} \\ \varepsilon_{y} \\ \varepsilon_{z}\end{array}\right\}$

Substituting Eq. (2.38) in the above gives

$$
\left(\sigma_{x}\right)_{K}=\left(\overline{Q_{11}}\right)_{K} \varepsilon_{x}=\left(\overline{Q_{11}}\right)_{K}\left[u^{\prime}+\frac{1}{2}\left(w^{\prime}\right)^{2}-z w^{\prime \prime}\right]
$$

\subsubsection{Virtual Strain Energy for Cylindrical Bending}

The total virtual strain energy for cylindrical bending is given as,

$\delta U=\iiint_{V}\left[\sigma_{x} \delta \varepsilon_{x}\right] d V$

where $\delta \varepsilon_{x}$ is the virtual strains and $V$ is the volume of the plate. The rectangular beam has width bin $y$ direction, length Lin $x$ axis and thickness $h$ in $z$ direction. Rewriting volume integral in terms of area and thickness integrals we get,

$\delta U=b \int_{0}^{L} \int_{-h / 2}^{h / 2} \sigma_{x} \delta \varepsilon_{x} d x d z$ 
Now the $\delta U$ can be written in terms of the deformation quantities as

$$
\begin{aligned}
& \delta U=b \int_{0}^{L}\left\{[ A _ { 1 1 } ( u ^ { \prime } + \frac { 1 } { 2 } ( w ^ { \prime } ) ^ { 2 } ) - B _ { 1 1 } w ^ { \prime \prime } ] ( \delta u ^ { \prime } + w ^ { \prime } \delta w ^ { \prime } ) \left[-B_{11}\left(u^{\prime}+\frac{1}{2}\left(w^{\prime}\right)^{2}\right)+\right.\right. \\
& \left.\left.D_{11} w^{11}\right] \delta w^{\prime \prime}\right\} d x
\end{aligned}
$$




\section{FINITE ELEMENT METHOD}

\subsection{Introduction}

The finite element method can be employed to solve partial differential equations where the domain is first discretized into small elements called finite elements. Figure 3.1 shows the classification of methods to solve partial differential equations. With the increase in number of elements or nodes or both, the finite element solution approaches analytical solution. Based on this $h$ version, $p$ version and $h-p$ version finite element formulations are available. In the $h$ version, accuracy generally increases with the increase in number of elements, in the $p$-version number of internal nodes is increased to improve the accuracy and in the $h-p$ version both elements and nodes are increased to attain accuracy. In the present research, the $h-p$ version is used.

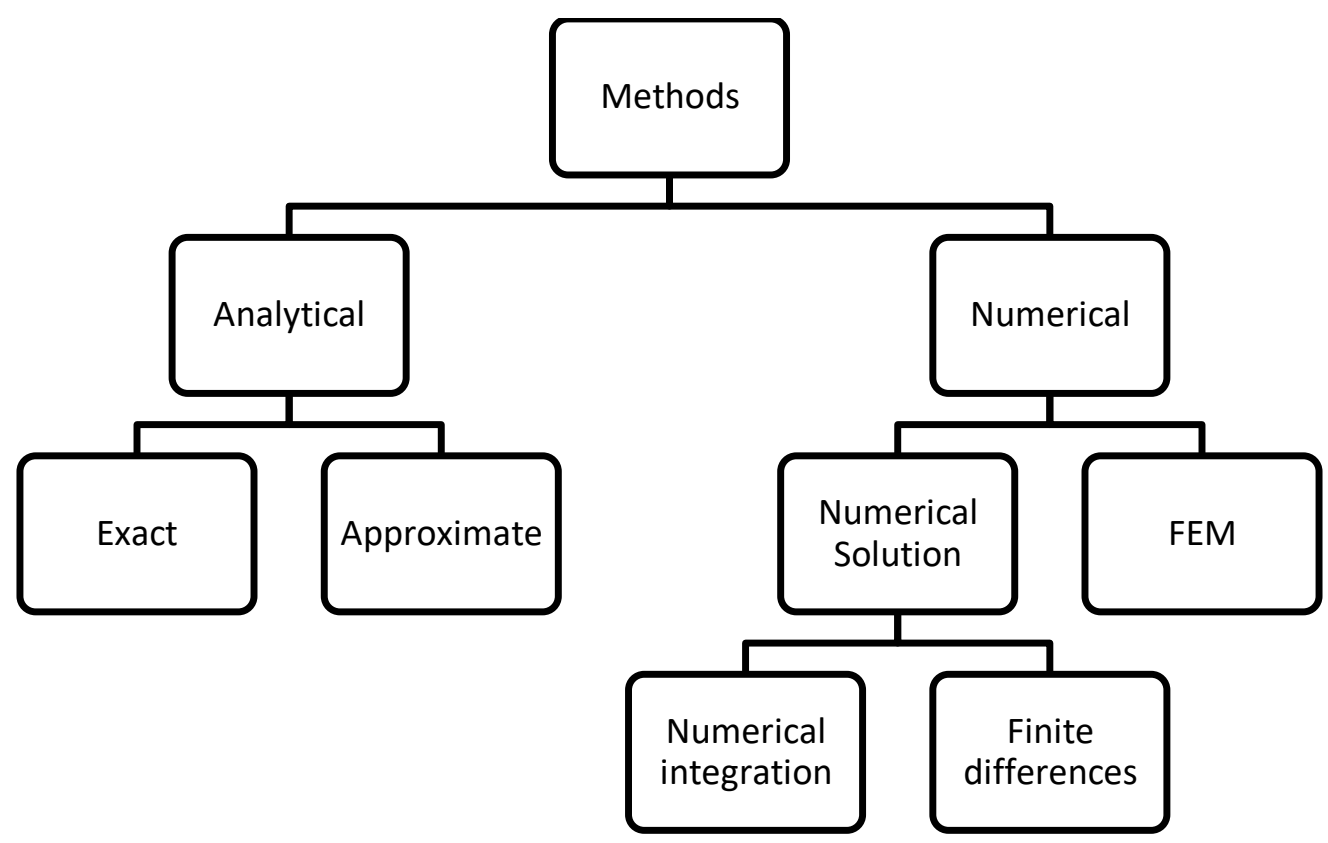

Fig. 3.1 Classification of methods to solve partial differential equations

\subsection{Finite element shape functions}

Sreeram and Sivaneri (1997) conducted a convergence study on an isotropic beam problem and concluded that four elements with three internal nodes each produce an accurate solution. In the present research, the composite beam is divided into four elements, each having three internal nodes and two end nodes. The $\mathrm{C}^{0}$ continuity is satisfied by certain variables and their shape functions are derived using Lagrangian interpolating polynomials while Hermitian polynomials are used in deriving other shape functions which obey $\mathrm{C}^{1}$ continuity. For the 
variables that employ $\mathrm{C}^{1}$ continuity, only the end nodes have slope degrees of freedom as the slope continuity at the internal nodes is automatically satisfied.

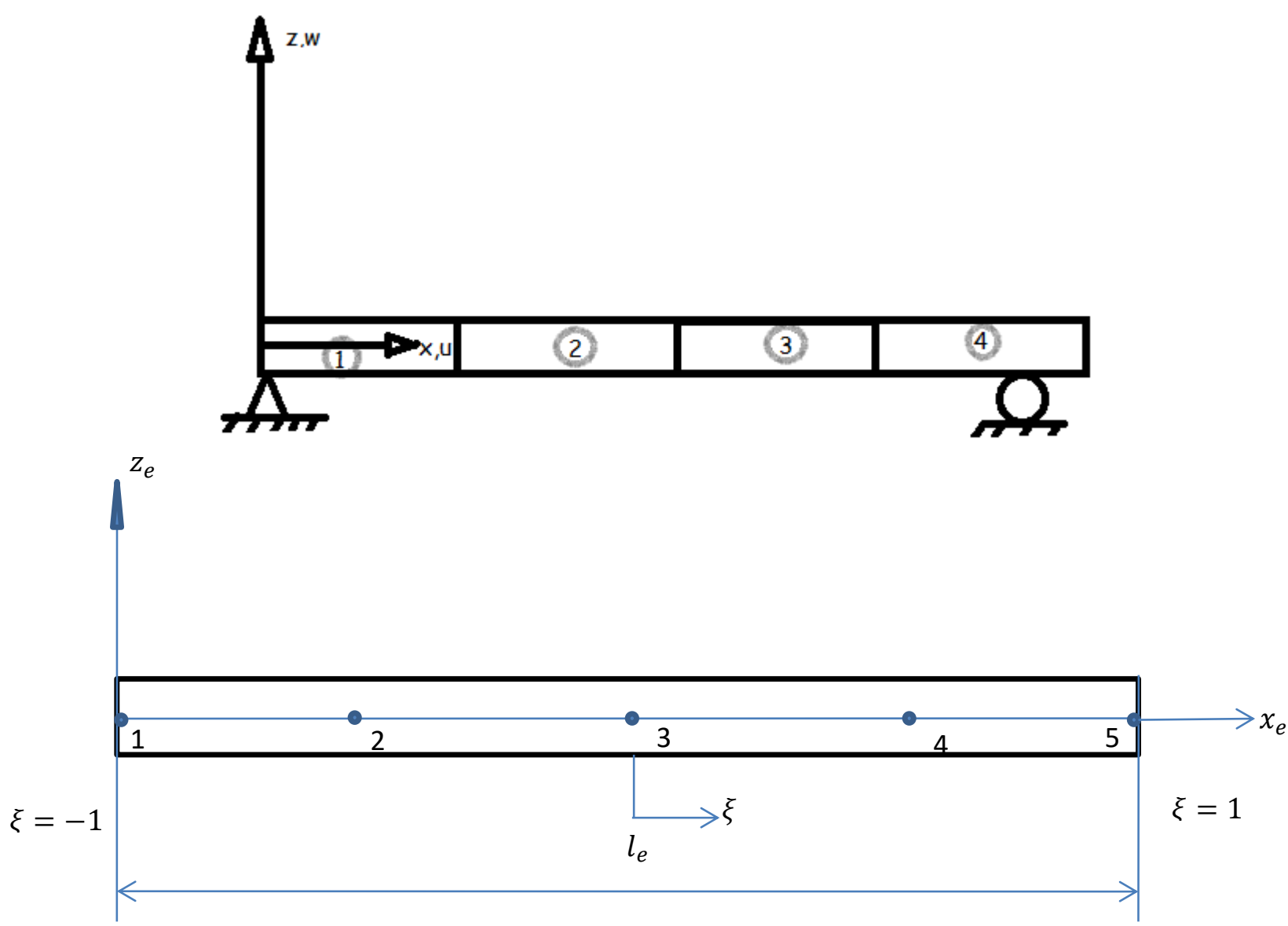

Fig. 3.2 Finite element beam representation and representation of an element with natural coordinates and three internal nodes

Figure 3.2 shows finite element beam representation. The beam considered is divided into four elements. Each element has three internal nodes and two end nodes. The length of the element is $l_{\mathrm{e}}, \xi$ is the natural coordinate and $x_{e}$ is the independent variable measured from left end of the beam. The dependent variables are:

$u=$ axial deformation at mid-plane

$\gamma=$ mid-plane shear strain

$w_{b}=$ transverse bending deformation

$w_{s}=$ transverse shear deformation 
$w_{b}^{y}=$ twist angle associated with the bending deformation

$w_{s}^{y}=$ twist angle associated with the shear deformation

The variables $u, \gamma, w_{b}^{y}, w_{s}^{y}$ obey $\mathrm{C}^{0}$ continuity while $w_{b}$ and $w_{s}$ have slope degrees of freedom at the end nodes and thus $\mathrm{C}^{1}$ continuity is assured.

For each element, an intrinsic coordinate $\xi$ ranging from -1 to 1 is described with its origin at the center as shown in Fig. 3.2. The elemental coordinates can be transformed to the intrinsic coordinates with the following relation

$$
\begin{gathered}
x_{e}=\frac{l_{e}}{2}(\xi+1) \\
d x_{e}=\frac{l_{e}}{2} d \xi
\end{gathered}
$$

where $l_{e}$ being element length. The shape functions for the variables that follow $\mathrm{C}^{0}$ continuity and $\mathrm{C}^{1}$ continuity are derived respectively. The axial displacement $(\mathrm{u})$ and lateral displacement component due to bending $\left(w_{b}\right)$ are represented as

$$
\begin{aligned}
& u(\xi)=\sum_{i=0}^{4} a_{i} \xi^{i} \\
& w(\xi)=\sum_{j=0}^{6} b_{i} \xi^{j}
\end{aligned}
$$

The above equations can be written in matrix form as follows

$$
\begin{aligned}
& u(\xi)=\left\lfloor\xi^{i}\right\rfloor\left\{a_{i}\right\} \\
& w(\xi)=\left\lfloor\xi^{j}\right\rfloor\left\{b_{j}\right\}
\end{aligned}
$$

Where the $a_{i}$ are determined by the following conditions

$$
\begin{aligned}
& u(-1)=u_{1} \\
& u(-0.5)=u_{2} \\
& u(0)=u_{3} \\
& u(0.5)=u_{4} \\
& u(1)=u_{5}
\end{aligned}
$$


By solving the above equations and substituting in Eq. (3.3) we get,

$u(\xi)=\left\lfloor H_{L 1}(\xi) \ldots H_{L 5}(\xi)\right\rfloor\left\{\begin{array}{c}u_{1} \\ \cdot \\ \cdot \\ \cdot \\ u_{5}\end{array}\right\}$

where $H_{L 1}(\xi), H_{L 2}(\xi) . . H_{L 5}(\xi)$ are called as Lagrange shape functions. They are

$H_{L 1}=\frac{1}{6} \xi-\frac{1}{6} \xi^{2}-\frac{2}{3} \xi^{3}+\frac{2}{3} \xi^{4}$

$H_{L 2}=-\frac{4}{3} \xi+\frac{8}{3} \xi^{2}+\frac{4}{3} \xi^{3}+\frac{8}{3} \xi^{4}$

$H_{L 3}=1-5 \xi^{2}+4 \xi^{4}$

$H_{L 4}=\frac{4}{3} \xi+\frac{8}{3} \xi^{2}-\frac{4}{3} \xi^{3}-\frac{8}{3} \xi^{4}$

$H_{L 5}=\frac{1}{6} \xi-\frac{1}{6} \xi^{2}-\frac{2}{3} \xi^{3}+\frac{2}{3} \xi^{4}$

And $b_{j}$ can be determined by the following conditions

$w_{b}(-1)=w_{b_{1}}$

$\frac{l_{e}}{2} \frac{d w_{b}}{d \xi}(-1)=w_{b_{1}}{ }^{\prime}$

$w_{b}(-0.5)=w_{b_{2}}$

$w_{b}(0)=w_{b_{3}}$

$w_{b}(0.5)=w_{b_{4}}$

$w_{b}(1)=w_{b_{5}}$

$\frac{l_{e}}{2} \frac{d w_{b}}{d \xi}(1)=w_{b_{5}}{ }^{\prime}$

Solving the above equations for $b_{j}$ we get, 
$w_{b}(\xi)=\left\lfloor H_{1}(\xi) \ldots H_{7}(\xi)\right\rfloor\left\{\begin{array}{c}w_{b_{1}} \\ w_{b_{1}}{ }^{\prime} \\ \cdot \\ \cdot \\ \cdot \\ w_{b_{5}}{ }^{\prime}\end{array}\right\}$

where $H_{1}(\xi), H_{2}(\xi) . . H_{5}(\xi)$ are called as Hermite shape functions. They are

$H_{1}=\frac{1}{9}\left(\frac{17}{4} \xi-5 \xi^{2}-\frac{79}{4} \xi^{3}+\frac{47}{2} \xi^{4}+11 \xi^{5}-14 \xi^{6}\right)$

$H_{2}=\frac{l_{e}}{6}\left(\frac{1}{4} \xi-\frac{1}{4} \xi^{2}-\frac{5}{4} \xi^{3}+\frac{5}{4} \xi^{4}+\xi^{5}-\xi^{6}\right)$

$H_{3}=\frac{16}{9}\left(-\xi+2 \xi^{2}+2 \xi^{3}-4 \xi^{4}-\xi^{5}+2 \xi^{6}\right)$

$H_{4}=1-6 \xi^{2}+9 \xi^{4}-4 \xi^{6}$

$H_{5}=\frac{16}{9}\left(\xi+2 \xi^{2}-2 \xi^{3}-4 \xi^{4}+\xi^{5}+2 \xi^{6}\right)$

$H_{6}=\frac{1}{9}\left(-\frac{17}{4} \xi-5 \xi^{2}+\frac{79}{4} \xi^{3}+\frac{47}{2} \xi^{4}-11 \xi^{5}-14 \xi^{6}\right)$

$H_{7}=\frac{l_{e}}{6}\left(\frac{1}{4} \xi+\frac{1}{4} \xi^{2}-\frac{5}{4} \xi^{3}-\frac{5}{4} \xi^{4}+\xi^{5}+\xi^{6}\right)$

\subsection{Element stiffness Matrix formulation}

The elemental stiffness matrix is obtained from the virtual strain energy equation reduced for the beam.

$$
\delta U_{e}=\left\lfloor\delta q_{e}\right\rfloor\left[K_{e}\right]\left\{q_{e}\right\}
$$

Where $U_{e}$ represents the elemental strain energy, $\left\{q_{e}\right\}$ denotes the vector of element degrees of freedom and $\left[K_{e}\right]$ represents the elemental stiffness matrix. The real and virtual displacement fields can be represented in terms of shape functions and the corresponding nodal degrees of freedom.

For example, expressions for mid-plane shear and bending displacements are given as,

$$
\begin{gathered}
\gamma(x)=\left\lfloor H_{L}\right\rfloor\left\{q_{\gamma}\right\} \\
\delta \gamma(x)=\left\lfloor\delta q_{\gamma}\right\rfloor\left\{H_{L}\right\}
\end{gathered}
$$




$$
\begin{gathered}
w_{b}(x)=\lfloor H\rfloor\left\{q_{w_{b}}\right\} \\
\delta w_{b}(x)=\left\lfloor\delta q_{w_{b}}\right\rfloor\{H\}
\end{gathered}
$$

where $\left\{q_{\gamma}\right\}$ and $\left\{q_{w_{b}}\right\}$ are the vectors of elemental nodal degrees of freedom for the variables $\gamma$ and $w_{b}$ respectively. Using these above expressions and similar ones for other variables in the virtual strain energy expression, Eq. (2.35), and then comparing with Eq. (3.10) we get the stiffness matrix.

The element stiffness matrix has linear and nonlinear parts as the governing equations are nonlinear. Each stiffness matrix is partitioned into 36 submatrices. The linear stiffness matrix is a symmetric matrix while the nonlinear stiffness matrix is not symmetrical.

\subsubsection{Linear Element Stiffness Matrix for HSDT}

The element has a total of 34 degrees of freedom. The stiffness matrix is partitioned into 36 submatrices. The following is the submatrix representation for the linear part of the element stiffness matrix.

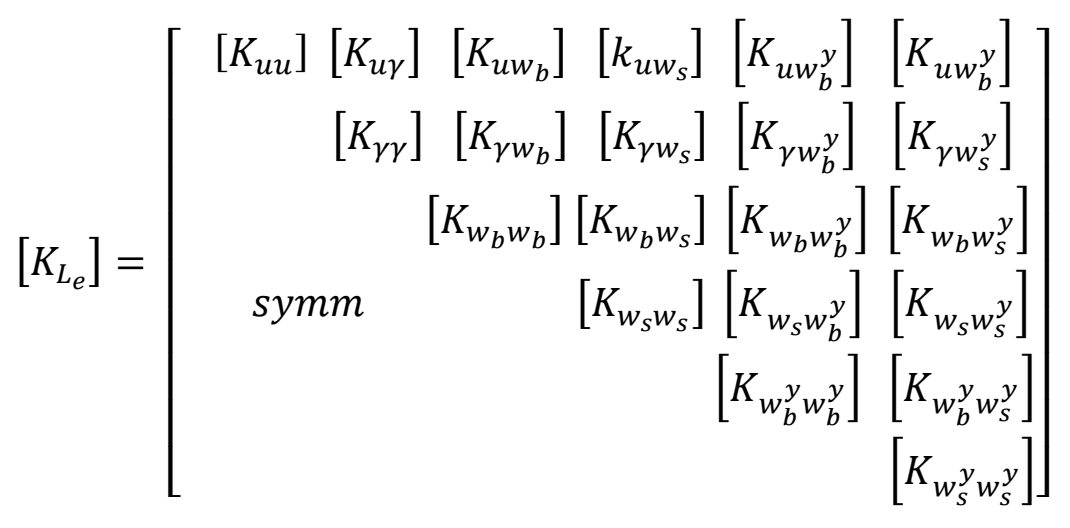

Where,

$$
\begin{aligned}
& {\left[K_{u u}\right]=b \int_{0}^{l_{e}} T_{11}\left\{H_{L}^{\prime}\right\}\left\lfloor H_{L}^{\prime}\right\rfloor d x_{e}} \\
& {\left[K_{u \gamma}\right]=b \int_{0}^{l_{e}} T_{12}\left\{H_{L}^{\prime}\right\}\left\lfloor H_{L}\right\rfloor d x_{e}} \\
& {\left[K_{u w_{b}}\right]=-b \int_{0}^{l_{e}} T_{13}\left\{H_{L}^{\prime}\right\}\left\lfloor H^{\prime \prime}\right\rfloor d x_{e}}
\end{aligned}
$$




$$
\begin{aligned}
& {\left[K_{u w_{s}}\right]=-b c_{1} \int_{0}^{l_{e}} T_{13}\left\{H_{L}^{\prime}\right\}\left\lfloor H^{\prime \prime}\right\rfloor d x_{e}} \\
& {\left[K_{u w_{b} y}\right]=-2 b \int_{0}^{l_{e}} T_{14}\left\{H_{L}^{\prime}\right\}\left\lfloor H_{L}^{\prime}\right\rfloor d x_{e}} \\
& {\left[K_{u w_{s}^{y}}\right]=-2 b c_{1} \int_{0}^{l_{e}} T_{16}\left\{H_{L}^{\prime}\right\}\left\lfloor H_{L}^{\prime}\right\rfloor d x_{e}} \\
& {\left[K_{\gamma \gamma}\right]=b \int_{0}^{l_{e}} T_{22}\left\{H_{L}\right\}\left\lfloor H_{L}\right\rfloor d x_{e}} \\
& {\left[K_{\gamma w_{b}}\right]=-b \int_{0}^{l_{e}} T_{23}\left\{H_{L}\right\}\left\lfloor H^{\prime \prime}\right\rfloor d x_{e}} \\
& {\left[K_{\gamma w_{s}}\right]=-b c_{1} \int_{0}^{l_{e}} T_{25}\left\{H_{L}\right\}\left\lfloor H^{\prime \prime}\right\rfloor d x_{e}} \\
& {\left[K_{\gamma w_{b} y}\right]=-2 b \int_{0}^{l_{e}} T_{24}\left\{H_{L}\right\}\left\lfloor H_{L}^{\prime}\right\rfloor d x_{e}} \\
& {\left[K_{\gamma w_{s}}\right]=-2 b c_{1} \int_{0}^{l_{e}} T_{26}\left\{H_{L}\right\}\left\lfloor H_{L}^{\prime}\right\rfloor d x_{e}} \\
& {\left[K_{w_{b} w_{b}}\right]=b \int_{0}^{l_{e}} T_{33}\left\{H^{\prime \prime}\right\}\left\lfloor H^{\prime \prime}\right\rfloor d x_{e}} \\
& {\left[K_{w_{b} w_{s}}\right]=b c_{1} \int_{0}^{l_{e}} T_{35}\left\{H^{\prime \prime}\right\}\left\lfloor H^{\prime \prime}\right\rfloor d x_{e}} \\
& {\left[K_{w_{b} w_{b}^{y}}\right]=2 b \int_{0}^{l_{e}} T_{34}\left\{H^{\prime \prime}\right\}\left\lfloor H_{L}^{\prime}\right\rfloor d x_{e}} \\
& {\left[K_{w_{b} w_{s}^{y}}\right]=2 b c_{1} \int_{0}^{l_{e}} T_{36}\left\{H^{\prime \prime}\right\}\left\lfloor H_{L}^{\prime}\right\rfloor d x_{e}}
\end{aligned}
$$

26 


$$
\begin{aligned}
& {\left[K_{w_{s} w_{s}}\right]=b \int_{0}^{l_{e}} D_{55}^{* *}\left\{H^{\prime}\right\}\left\lfloor H^{\prime}\right\rfloor d x_{e}+b c_{1}^{2} \int_{0}^{l_{e}} T_{55}\left\{H^{\prime \prime}\right\}\left\lfloor H^{\prime \prime}\right\rfloor d x_{e}} \\
& {\left[K_{w_{s} w_{b}^{y}}\right]=2 b c_{1} \int_{0}^{l_{e}} T_{54}\left\{H^{\prime \prime}\right\}\left\lfloor H_{L}^{\prime}\right\rfloor d x_{e}} \\
& {\left[K_{w_{s} w_{s}^{y}}\right]=2 b c_{1}^{2} \int_{0}^{l_{e}} T_{56}\left\{H^{\prime \prime}\right\}\left\lfloor H_{L}^{\prime}\right\rfloor d x_{e}} \\
& {\left[K_{\left.w_{b}^{y} w_{b}^{y}\right]}=4 b \int_{0}^{l_{e}} T_{44}\left\{H_{L}^{\prime}\right\}\left\lfloor H_{L}^{\prime}\right\rfloor d x_{e}\right.} \\
& {\left[K_{\left.w_{b}^{y} w_{s}^{y}\right]}=4 b c_{1} \int_{0}^{l_{e}} T_{46}\left\{H_{L}^{\prime}\right\}\left\lfloor H_{L}^{\prime}\right\rfloor d x_{e}\right.} \\
& {\left[K_{w_{s}^{y} w_{s}^{y}}\right]=4 b c_{1}^{2} \int_{0}^{l_{e}} T_{66}\left\{H_{L}^{\prime}\right\}\left\lfloor H_{L}^{\prime}\right\rfloor d x_{e}}
\end{aligned}
$$

\subsubsection{Nonlinear Element Stiffness Matrix for HSDT}

The following is the submatrix representation for the nonlinear part of the stiffness matrix.

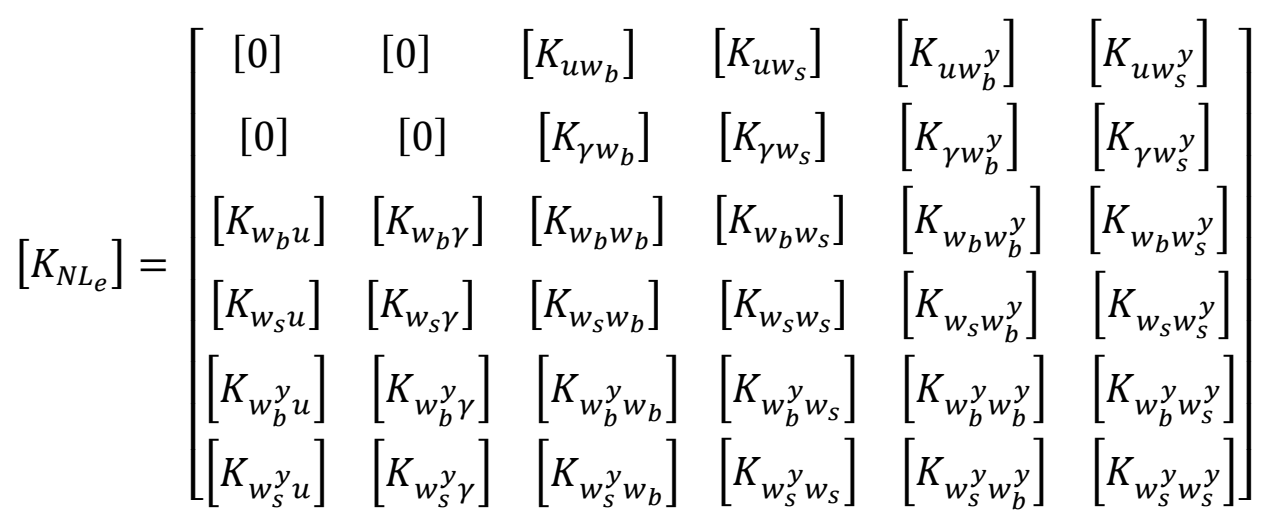

Where,

$$
\begin{aligned}
& {\left[K_{u w_{b}}\right]=b \int_{0}^{l_{e}} \frac{T_{11}}{2} w_{b}^{\prime}\left\{H_{L}^{\prime}\right\}\left\lfloor H^{\prime}\right\rfloor d x_{e}} \\
& {\left[K_{u w_{s}}\right]=b \int_{0}^{l_{e}} \frac{T_{11}}{2} w_{s}^{\prime}\left\{H_{L}^{\prime}\right\}\left\lfloor H^{\prime}\right\rfloor d x_{e}}
\end{aligned}
$$




$$
\begin{aligned}
& {\left[K_{u w_{b}^{y}}\right]=b \int_{0}^{l_{e}} T_{12}\left(w_{b}^{\prime}+w_{s}^{\prime}\right)\left\{H_{L}^{\prime}\right\}\left\lfloor H^{\prime}\right\rfloor d x_{e}=\left[K_{u w_{s}^{y}}\right]} \\
& \left.\left[K_{\gamma w_{b}}\right]=b \int_{0}^{l_{e}} \frac{T_{21}}{2} w_{b}^{\prime}\left\{H_{L}\right\} \mid H^{\prime}\right\rfloor d x_{e} \\
& {\left[K_{\gamma w_{s}}\right]=b \int_{0}^{l_{e}} \frac{T_{21}}{2} w_{s}^{\prime}\left\{H_{L}\right\}\left\lfloor H^{\prime}\right\rfloor d x_{e}} \\
& {\left[K_{\gamma w_{b}^{y}}\right]=b \int_{0}^{l_{e}} T_{22}\left(w_{b}^{\prime}+w_{s}^{\prime}\right)\left\{H_{L}\right\}\left\lfloor H_{L}\right\rfloor d x_{e}=\left[K_{\gamma w_{s}^{y}}\right]} \\
& {\left[K_{w_{b} u}\right]=b \int_{0}^{l_{e}} T_{11} w_{b}^{\prime}\left\{H^{\prime}\right\}\left\lfloor H_{L}^{\prime}\right\rfloor d x_{e}+b \int_{0}^{l_{e}} T_{12}\left(w_{b}^{y}+w_{s}^{y}\right)\left\{H^{\prime}\right\}\left\lfloor H_{L}^{\prime}\right\rfloor d x_{e}} \\
& {\left[K_{w_{b} \gamma}\right]=b \int_{0}^{l_{e}} T_{12} w_{b}^{\prime}\left\{H^{\prime}\right\}\left\lfloor H_{L}^{\prime}\right\rfloor d x_{e}+b \int_{0}^{l_{e}} T_{22}\left(w_{b}^{y}+w_{s}^{y}\right)\left\{H^{\prime}\right\}\left\lfloor H_{L}^{\prime}\right\rfloor d x_{e}} \\
& {\left[K_{w_{b} w_{b}}\right]=-b \int_{0}^{l_{e}}\left(\frac{T_{31}}{2} w_{b}^{\prime}\left\{H^{\prime \prime}\right\}\left\lfloor H^{\prime}\right\rfloor-T_{13} w_{b}^{\prime}\left\{H^{\prime}\right\}\left\lfloor H^{\prime \prime}\right\rfloor-\frac{T_{11}}{2}\left(w_{b}^{\prime}\right)^{2}\left\{H^{\prime}\right\}\left\lfloor H^{\prime}\right\rfloor\right.} \\
& \left.+T_{23}\left(w_{b}^{y}+w_{s}^{y}\right)\left\{H^{\prime}\right\}\left\lfloor H^{\prime \prime}\right\rfloor+\frac{T_{21}}{2}\left(w_{b}^{y}+w_{s}^{y}\right) w_{b}^{\prime}\left\{H^{\prime}\right\}\left[H^{\prime}\right\rfloor\right) d x_{e} \\
& {\left[K_{w_{b} w_{s}}\right]=-b \int_{0}^{l_{e}}\left(\frac{T_{31}}{2} w_{s}^{\prime}\left\{H^{\prime \prime}\right\}\left\lfloor H^{\prime}\right\rfloor+c_{1} T_{15} w_{b}^{\prime}\left\{H^{\prime}\right\}\left[H^{\prime \prime}\right]-\frac{T_{11}}{2}\left(w_{b}^{\prime} w_{s}^{\prime}\right)\left\{H^{\prime}\right\}\left[H^{\prime}\right\rfloor\right.} \\
& \left.+c_{1} T_{25}\left(w_{b}^{y}+w_{s}^{y}\right)\left\{H^{\prime}\right\}\left\lfloor H^{\prime \prime}\right\rfloor-\frac{T_{21}}{2}\left(w_{b}^{y}+w_{s}^{y}\right) w_{s}^{\prime}\left\{H^{\prime}\right\}\left\lfloor H^{\prime}\right\rfloor\right) d x_{e} \\
& {\left[K_{w_{b} w_{b}^{y}}\right]=b \int_{0}^{l_{e}}\left(-T_{32}\left(w_{b}^{\prime}+w_{s}^{\prime}\right)\left\{H^{\prime \prime}\right\}\left\lfloor H_{L}\right\rfloor-2 T_{14} w_{b}^{\prime}\left\{H^{\prime}\right\}\left\lfloor H_{L}^{\prime}\right\rfloor+T_{12} w_{b}^{\prime}\left(w_{b}^{\prime}+w_{s}^{\prime}\right)\left\{H^{\prime}\right\} \mid H_{L}\right\rfloor} \\
& \left.-2 T_{24}\left(w_{b}^{y}+w_{s}^{y}\right)\left\{H^{\prime}\right\}\left\lfloor H_{L}^{\prime}\right\rfloor+T_{22}\left(w_{b}^{\prime}+w_{s}^{\prime}\right)\left\{H^{\prime}\right\}\left\lfloor H_{L}\right\rfloor\right) d x_{e} \\
& {\left[K_{w_{b} w_{s}^{y}}\right]=b \int_{0}^{l_{e}}\left(-T_{32}\left(w_{b}^{\prime}+w_{s}^{\prime}\right)\left\{H^{\prime \prime}\right\}\left\lfloor H_{L}\right\rfloor-2 T_{16} w_{b}^{\prime}\left\{H^{\prime}\right\}\left\lfloor H_{L}^{\prime}\right\rfloor+T_{12} w_{b}^{\prime}\left(w_{b}^{\prime}+w_{s}^{\prime}\right)\left\{H^{\prime}\right\}\left\lfloor H_{L}\right\rfloor\right.} \\
& \left.-2 c_{1} T_{26}\left(w_{b}^{y}+w_{s}^{y}\right)\left\{H^{\prime}\right\}\left\lfloor H_{L}^{\prime}\right\rfloor+T_{22}\left(w_{b}^{\prime}+w_{s}^{\prime}\right)\left\{H^{\prime}\right\}\left\lfloor H_{L}\right\rfloor\right) d x_{e}
\end{aligned}
$$




$$
\begin{aligned}
& {\left[K_{w_{s} u}\right]=b \int_{0}^{l_{e}} T_{11} w_{s}^{\prime}\left\{H^{\prime}\right\}\left\lfloor H_{L}^{\prime}\right\rfloor d x_{e}+b \int_{0}^{l_{e}} T_{12}\left(w_{b}^{y}+w_{s}^{y}\right)\left\{H^{\prime}\right\}\left\lfloor H_{L}^{\prime}\right\rfloor d x_{e}} \\
& {\left[K_{w_{s} \gamma}\right]=b \int_{0}^{l_{e}} T_{12} w_{s}^{\prime}\left\{H^{\prime}\right\}\left\lfloor H_{L}^{\prime}\right\rfloor d x_{e}+b \int_{0}^{l_{e}} T_{22}\left(w_{b}^{y}+w_{s}^{y}\right)\left\{H^{\prime}\right\}\left\lfloor H_{L}^{\prime}\right\rfloor d x_{e}} \\
& {\left[K_{w_{s} w_{b}}\right]=b \int_{0}^{l_{e}}\left(-c_{1} \frac{T_{51}}{2} w_{b}^{\prime}\left\{H^{\prime \prime}\right\}\left\lfloor H^{\prime}\right\rfloor-T_{13} w_{s}^{\prime}\left\{H^{\prime}\right\}\left[H^{\prime \prime}\right\rfloor-\frac{T_{11}}{2}\left(w_{s}^{\prime} w_{b}^{\prime}\right)\left\{H^{\prime}\right\}\left\lfloor H^{\prime}\right\rfloor\right.} \\
& \left.+T_{23}\left(w_{b}^{y}+w_{s}^{y}\right)\left\{H^{\prime}\right\}\left\lfloor H^{\prime \prime}\right\rfloor+\frac{T_{21}}{2}\left(w_{b}^{y}+w_{s}^{y}\right) w_{b}^{\prime}\left\{H^{\prime}\right\}\left\lfloor H^{\prime}\right\rfloor\right) d x_{e} \\
& {\left[K_{w_{s} w_{s}}\right]=b \int_{0}^{l_{e}}\left(-c_{1} \frac{T_{51}}{2} w_{s}^{\prime}\left\{H^{\prime \prime}\right\}\left[H^{\prime}\right\rfloor-c_{1} T_{15} w_{s}^{\prime}\left\{H^{\prime}\right\}\left[H^{\prime \prime}\right\rfloor+\frac{T_{11}}{2}\left(w_{s}^{\prime}\right)^{2}\left\{H^{\prime}\right\} \mid H^{\prime}\right\rfloor} \\
& \left.-c_{1} T_{25}\left(w_{b}^{y}+w_{s}^{y}\right)\left\{H^{\prime}\right\}\left\lfloor H^{\prime \prime}\right\rfloor+\frac{T_{21}}{2}\left(w_{b}^{y}+w_{s}^{y}\right) w_{s}^{\prime}\left\{H^{\prime}\right\}\left\lfloor H^{\prime}\right\rfloor\right) d x_{e} \\
& {\left[K_{w_{s} w_{b}^{y}}\right]=b \int_{0}^{l_{e}}\left(-c_{1} T_{52}\left(w_{b}^{\prime}+w_{s}^{\prime}\right)\left\{H^{\prime \prime}\right\}\left\lfloor H_{L}\right\rfloor-2 T_{14} w_{s}^{\prime}\left\{H^{\prime}\right\}\left\lfloor H_{L}^{\prime}\right\rfloor+T_{12} w_{s}^{\prime}\left(w_{b}^{\prime}+w_{s}^{\prime}\right)\left\{H^{\prime}\right\}\left\lfloor H_{L}\right\rfloor\right.} \\
& \left.-2 T_{24}\left(w_{b}^{y}+w_{s}^{y}\right)\left\{H^{\prime}\right\}\left\lfloor H_{L}^{\prime}\right\rfloor+T_{22}\left(w_{b}^{\prime}+w_{s}^{\prime}\right)\left\{H^{\prime}\right\}\left\lfloor H_{L}\right\rfloor\right) d x_{e} \\
& {\left[K_{w_{s} w_{s}^{y}}\right]=b \int_{0}^{l_{e}}\left(-c_{1} T_{52}\left(w_{b}^{\prime}+w_{s}^{\prime}\right)\left\{H^{\prime \prime}\right\}\left\lfloor H_{L}\right\rfloor-2 T_{16} w_{s}^{\prime}\left\{H^{\prime}\right\}\left\lfloor H_{L}^{\prime}\right\rfloor+T_{12} w_{s}^{\prime}\left(w_{b}^{\prime}+w_{s}^{\prime}\right)\left\{H^{\prime}\right\}\left\lfloor H_{L}\right\rfloor\right.} \\
& \left.-2 c_{1} T_{26}\left(w_{b}^{y}+w_{s}^{y}\right)\left\{H^{\prime}\right\}\left\lfloor H_{L}^{\prime}\right\rfloor+T_{22}\left(w_{b}^{\prime}+w_{s}^{\prime}\right)\left\{H^{\prime}\right\}\left\lfloor H_{L}\right\rfloor\right) d x_{e} \\
& {\left[K_{w_{b}^{y} u}\right]=b \int_{0}^{l_{e}}\left(T_{21}\left(w_{b}^{\prime}+w_{s}^{\prime}\right)\left\{H_{L}\right\}\left\lfloor H_{L}^{\prime}\right\rfloor\right) d x_{e}} \\
& \left.\left[K_{w_{b}^{y} \gamma}\right]=b \int_{0}^{l_{e}}\left(T_{22}\left(w_{b}^{\prime}+w_{s}^{\prime}\right)\left\{H_{L}\right\} \mid H_{L}\right\rfloor\right) d x_{e} \\
& {\left[K_{w_{b}^{y}} w_{b}\right]=b \int_{0}^{l_{e}}\left(-2 \frac{T_{41}}{2} w_{b}^{\prime}\left\{H_{L}^{\prime}\right\}\left[H^{\prime}\right\rfloor-T_{23}\left(w_{b}^{\prime}+w_{s}^{\prime}\right)\left\{H_{L}\right\}\left[H^{\prime \prime}\right\rfloor+\frac{T_{21}}{2}\left(w_{b}^{\prime}+w_{s}^{\prime}\right) w_{b}^{\prime}\left\{H_{L}\right\}\left[H^{\prime \prime}\right\rfloor\right) d x_{e}} \\
& {\left[K_{w_{b}^{y}} w_{s}\right]=b \int_{0}^{l_{e}}\left(-2 \frac{T_{41}}{2} w_{s}^{\prime}\left\{H_{L}^{\prime}\right\}\left\lfloor H^{\prime}\right\rfloor-c_{1} T_{25}\left(w_{b}^{\prime}+w_{s}^{\prime}\right)\left\{H_{L}\right\}\left\lfloor H^{\prime \prime}\right\rfloor+\frac{T_{21}}{2}\left(w_{b}^{\prime}+w_{s}^{\prime}\right) w_{s}^{\prime}\left\{H_{L}\right\}\left\lfloor H^{\prime \prime}\right\rfloor\right) d x_{e}}
\end{aligned}
$$




$$
\begin{aligned}
& {\left[K_{w_{b}} w_{b}^{y}\right]=b \int_{0}^{l_{e}}\left(-2 T_{42}\left(w_{b}^{\prime}+w_{s}^{\prime}\right)\left\{H_{L}^{\prime}\right\}\left\lfloor H_{L}\right\rfloor-2 T_{24}\left(w_{b}^{\prime}+w_{s}^{\prime}\right)\left\{H_{L}\right\}\left\lfloor H_{L}^{\prime}\right\rfloor+T_{22}\left(w_{b}^{\prime}+w_{s}^{\prime}\right)^{2}\left\{H_{L}\right\}\left\lfloor H_{L}\right\rfloor\right) d x_{e}} \\
& {\left[K_{w_{b}^{y}} w_{s}^{y}\right]=b \int_{0}^{l_{e}}\left(-2 T_{42}\left(w_{b}^{\prime}+w_{s}^{\prime}\right)\left\{H_{L}^{\prime}\right\}\left\lfloor H_{L}\right\rfloor-2 c_{1} T_{26}\left(w_{b}^{\prime}+w_{s}^{\prime}\right)\left\{H_{L}\right\}\left\lfloor H_{L}^{\prime}\right\rfloor\right.} \\
& \left.+T_{22}\left(w_{b}^{\prime}+w_{S}^{\prime}\right)^{2}\left\{H_{L}\right\}\left\lfloor H_{L}\right\rfloor\right) d x_{e} \\
& {\left[K_{w_{s}} u\right]=b \int_{0}^{l_{e}}\left(T_{21}\left(w_{b}^{\prime}+w_{s}^{\prime}\right)\left\{H_{L}\right\}\left\lfloor H_{L}^{\prime}\right\rfloor\right) d x_{e}} \\
& {\left[K_{w_{s}}{ }\right]=b \int_{0}^{l_{e}}\left(T_{22}\left(w_{b}^{\prime}+w_{s}^{\prime}\right)\left\{H_{L}\right\}\left\lfloor H_{L}\right\rfloor\right) d x_{e}} \\
& {\left[K_{w_{s}} w_{b}\right]=b \int_{0}^{l_{e}}\left(-2 c_{1} \frac{T_{61}}{2} w_{b}^{\prime}\left\{H_{L}^{\prime}\right\}\left\lfloor H^{\prime}\right\rfloor-T_{23}\left(w_{b}^{\prime}+w_{s}^{\prime}\right)\left\{H_{L}\right\}\left\lfloor H^{\prime \prime}\right\rfloor+\frac{T_{21}}{2}\left(w_{b}^{\prime}+w_{s}^{\prime}\right) w_{b}^{\prime}\left\{H_{L}\right\}\left\lfloor H^{\prime \prime}\right\rfloor\right) d x_{e}} \\
& {\left[K_{w_{s} w_{s}}\right]=b \int_{0}^{l_{e}}\left(-2 c_{1} \frac{T_{61}}{2} w_{s}^{\prime}\left\{H_{L}^{\prime}\right\}\left\lfloor H^{\prime}\right\rfloor-c_{1} T_{25}\left(w_{b}^{\prime}+w_{s}^{\prime}\right)\left\{H_{L}\right\}\left\lfloor H^{\prime \prime}\right\rfloor\right.} \\
& \left.+\frac{T_{21}}{2}\left(w_{b}^{\prime}+w_{s}^{\prime}\right) w_{s}^{\prime}\left\{H_{L}\right\}\left\lfloor H^{\prime \prime}\right\rfloor\right) d x_{e} \\
& {\left[K_{w_{s}} w_{b}^{y}\right]=b \int_{0}^{l_{e}}\left(-2 c_{1} T_{62}\left(w_{b}^{\prime}+w_{s}^{\prime}\right)\left\{H_{L}^{\prime}\right\}\left\lfloor H_{L}\right\rfloor-2 T_{24}\left(w_{b}^{\prime}+w_{s}^{\prime}\right)\left\{H_{L}\right\}\left\lfloor H_{L}^{\prime}\right\rfloor\right.} \\
& \left.+T_{22}\left(w_{b}^{\prime}+w_{s}^{\prime}\right)^{2}\left\{H_{L}\right\}\left\lfloor H_{L}\right\rfloor\right) d x_{e} \\
& {\left[K_{w_{s}} w_{s}^{y}\right]=} \\
& b \int_{0}^{l_{e}}\left(-2 c_{1} T_{62}\left(w_{b}^{\prime}+w_{s}^{\prime}\right)\left\{H_{L}^{\prime}\right\}\left\lfloor H_{L}\right\rfloor-2 c_{1} T_{26}\left(w_{b}^{\prime}+w_{S}^{\prime}\right)\left\{H_{L}\right\}\left\lfloor H_{L}^{\prime}\right\rfloor+T_{22}\left(w_{b}^{\prime}+w_{S}^{\prime}\right)^{2}\left\{H_{L}\right\}\left\lfloor H_{L}\right\rfloor\right) d x_{e}(3.16) \\
& \text { wherec } c_{1}=\frac{4}{3 h^{2}}
\end{aligned}
$$

\subsection{Elemental Stiffness matrix for Cylindrical Bending}

The expression for elemental stiffness matrix for cylindrical bending is derived following a procedure similar to the one used for the element stiffness matrix for the HSDT. The number of dependent variables is two and they are $u$ and $w$. The $C^{0}$ continuity is used for $u$ variable whereas variable $w$ follows $C^{1}$ continuity. The element has 12 degrees of freedom. The stiffness 
matrix is subdivided into four submatrices. The stiffness submatrix $\left[K_{u u}\right]$ is the only linear part whereas the other three submatrices contain nonlinear terms.

$\left[K_{e}\right]=\left[\begin{array}{ll}{\left[K_{u u}\right]} & {\left[K_{u w}\right]} \\ {\left[K_{w u}\right]} & {\left[K_{w w}\right]}\end{array}\right]$

Where

$$
\begin{aligned}
{\left[K_{u u}\right] } & =b \int_{0}^{l_{e}} A_{11}\left\{H_{L}^{\prime}\right\}\left\lfloor H_{L}^{\prime}\right\rfloor d x_{e} \\
{\left[K_{u w}\right] } & =b \int_{0}^{l_{e}} \frac{1}{2} A_{11} w^{\prime}\left\{H_{L}^{\prime}\right\}\left\lfloor H^{\prime}\right\rfloor d x_{e}-b \int_{0}^{l_{e}} B_{11}\left\{H_{L}^{\prime}\right\}\left\lfloor H^{\prime \prime}\right\rfloor d x_{e} \\
{\left[K_{w u}\right] } & =b \int_{0}^{l_{e}} A_{11} w^{\prime}\left\{H^{\prime}\right\}\left\lfloor H_{L}^{\prime}\right\rfloor d x_{e}-b \int_{0}^{l_{e}} B_{11}\left\{H^{\prime \prime}\right\}\left\lfloor H_{L}^{\prime}\right\rfloor d x_{e} \\
{\left[K_{w w}\right] } & =b \int_{0}^{l_{e}} \frac{1}{2} A_{11}\left(w^{\prime}\right)^{2}\left\{H^{\prime}\right\}\left\lfloor H^{\prime}\right\rfloor d x_{e}-b \int_{0}^{l_{e}} B_{11} w^{\prime}\left\{H^{\prime}\right\}\left\lfloor H^{\prime \prime}\right\rfloor d x_{e}-b \int_{0}^{l_{e}} \frac{1}{2} B_{11} w^{\prime}\left\{H^{\prime \prime}\right\}\left\lfloor H^{\prime}\right\rfloor d x_{e} \\
& +b \int_{0}^{l_{e}} D_{11}\left\{H^{\prime \prime}\right\}\left\lfloor H^{\prime \prime}\right\rfloor d x_{e}
\end{aligned}
$$

\subsection{Finite element Equation}

The elemental stiffness matrix $\left[K_{e}\right]$ derived in the previous section is for the individual elements. The elemental stiffness for all the elements are assembled to form the global stiffness matrix $[K(q)]$. The global finite element equations are:

$$
[K(q)]\{q\}=\{Q\}
$$

where $[K(q)]$ is the global stiffness matrix. It has both linear and nonlinear stiffness matrices. Thus, global stiffness matrix is a function of $q,\{q\}$ is the degrees of freedom vector and $\{Q\}$ is the load vector. The expression for elemental load vector is as follows

$$
Q_{e}=\int_{0}^{l_{e}} p_{z}\left\{H\left(x_{e}\right)\right\} d x_{e}
$$

In natural coordinates, 


$$
Q_{e}=\int_{-1}^{+1} p_{z}\{H(\xi)\} \frac{l_{e}}{2} d \xi
$$

Where the $H(\xi)$ represent shape functions and $\mathrm{p}_{z}$ is the distributed load. Depending on the variable, the shape functions can be either Hermite or Lagrange polynomials.

The nonlinear finite element equations are solved using the Newton-Raphson iterative process. The size of global stiffness matrix is $112 \times 112$, the global degrees of freedom vector is $112 \times 1$ and global load vector is $112 \times 1$.

\subsection{NUMERICAL METHODS}

\subsubsection{Gaussian Quadrature}

The numerical method employed in this research for spatial integration is the Gaussian Quadrature. This technique is used for computing both the linear and nonlinear element stiffness matrices as they involve spatial integration. The integration scheme is represented in the following way

$$
\int_{-1}^{1} f(\xi) d \xi=\sum_{i=1}^{m} w_{i} f\left(a_{i}\right)
$$

where $\mathrm{m}$ is the number of sampling points, $a_{i}$ represent the natural coordinate $\xi$ at the sampling points and $w_{i}$ are the corresponding weights.

For a polynomial of order $(2 m-1)$,the Gauss quadrature requires $m$ sampling points to perform exact integration. In the present work, highest order of polynomial is fourteen. Thus, seven sampling points are required. They are listed below, along with their respective weights.

Table 3.1Gauss Quadrature sample points and weights

\begin{tabular}{|c|c|}
\hline Sampling points & Weights \\
\hline \pm 0.9491079123 & 0.1294849661 \\
\hline \pm 0.7415311855 & 0.0797053914 \\
\hline \pm 0.4058451513 & 0.3813005050 \\
\hline 0.0000000000 & 0.4179591836 \\
\hline
\end{tabular}




\subsubsection{Newton-Raphson Iterative Method}

In general, nonlinear finite element equations are solved using an incremental formulation in which the variables are updated incrementally with corresponding successive load steps to trace the path of the solution [Reddy (1997)],[Bathe and Cimento (1980), Felippa (1976), Bathe, Ramm and Wilson (1973), Bathe $(1976,1977,1979)]$. In the iterative method, the nonlinear equations are linearized by evaluating the nonlinear terms with a known solution. In this approach it is important that the governing finite element equations are satisfied in each load step. The accuracy of the solution depends on the size of the load step. To attain accurate result, a small load step need to be taken, thus making the analysis expensive and time consuming. To overcome this problem, an iterative method should be chosen in such a way that larger load steps assure the accuracy of the solutions. The Newton-Raphson method, based on Taylor's series expansion serves the need. This method is based on the tangent stiffness matrix, which is symmetric for all structural problems though direct stiffness matrix, $[K]$, is not symmetric. Also, this method has faster convergence for most applications than the direct iteration method. Suppose that the solution at $r^{\text {th }}$ iteration, $\{q\}^{r}$, is known.

Let

$$
\{R\} \equiv[K]\{q\}-\{Q\}=0
$$

Where $\{R\}$ is called the residual, which is a nonlinear function of the unknown solution $\{q\}$ and the increment of the solution vector is defined by,

$$
\{\delta q\}=-\left(\left[K\left(\{q\}^{r}\right)\right]^{\tan }\right)^{-1}\{R\}^{r}
$$

And the total solution at $(r+1)^{\text {th }}$ iteration is given by,

$$
\{q\}^{r+1}=\{q\}^{r}+\{\delta q\}
$$

The iteration process is continued by solving Eq. (3.24) until a convergence criterion is satisfied.

The error criterion is of the form

$$
\sqrt{\frac{\sum_{I=1}^{N}\left|q_{I}^{r+1}-q_{I}^{r}\right|^{2}}{\sum_{I=1}^{N}\left|q_{I}^{r+1}\right|^{2}}}<\epsilon\left(\operatorname{say} 10^{-3}\right)
$$

The coefficients of submatrices of element tangent stiffness matrix is defined as follows 


$$
\begin{aligned}
\left(K_{i j}^{\alpha \beta}\right)^{\tan } & \equiv \frac{\partial R_{i}^{\alpha}}{\partial q_{j}^{\beta}} \\
& \equiv K_{i j}^{\alpha \beta}+\bar{K}_{i j}^{\alpha \beta}
\end{aligned}
$$

Where

$$
\bar{K}_{i j}^{\alpha \beta}=\sum_{\gamma=1}^{5} \sum_{l=1}^{n} \frac{\partial K_{i l}^{\alpha \gamma}}{\partial q_{j}^{\beta}} q_{l}^{\gamma}
$$

The elemental tangential stiffness matrix obtained for HSDT is a symmetrical about its diagonal and is as show below

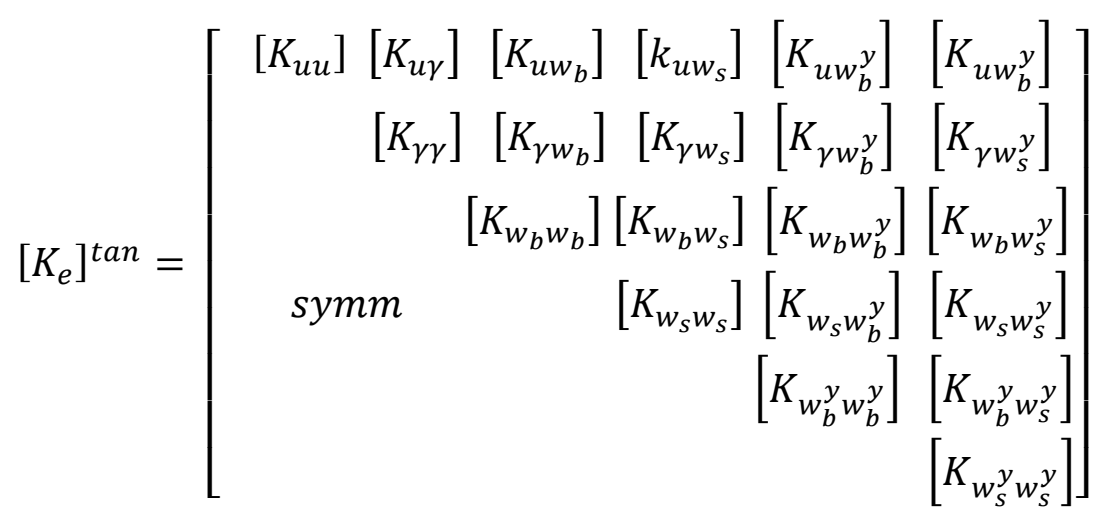

The coefficients of submatrices of element tangential stiffness matrix for HSDT are derived and listed below

$$
\begin{aligned}
& \left(K_{i j}^{11}\right)^{\tan }=K_{i j}^{11} \\
& \left(K_{i j}^{12}\right)^{\tan }=K_{i j}^{12} \\
& \left(K_{i j}^{13}\right)^{\tan }=\left[K_{u w_{b}}\right]+b \int_{0}^{l_{e}}\left\{\frac{T_{11}}{2} w_{b}^{\prime}\left\{H_{L}^{\prime}\right\}\left\lfloor H^{\prime}\right\rfloor+T_{12}\left(w_{b}^{y}+w_{s}^{y}\right)\left\{H_{L}^{\prime}\right\}\left\lfloor H^{\prime}\right\rfloor\right\} d x_{e} \\
& \left(K_{i j}^{14}\right)^{\tan }=\left[K_{u w_{s}}\right]+b \int_{0}^{l_{e}}\left\{\frac{T_{11}}{2} w_{s}^{\prime}\left\{H_{L}^{\prime}\right\}\left\lfloor H^{\prime}\right\rfloor+T_{12}\left(w_{b}^{y}+w_{s}^{y}\right)\left\{H_{L}^{\prime}\right\}\left\lfloor H^{\prime}\right\rfloor\right\} d x_{e} \\
& \left(K_{i j}^{15}\right)^{\tan }=K_{i j}^{15} \\
& \left(K_{i j}^{16}\right)^{\tan }=K_{i j}^{16}
\end{aligned}
$$




$$
\begin{aligned}
& \left(K_{i j}^{22}\right)^{\tan }=K_{i j}^{22} \\
& \left(K_{i j}^{23}\right)^{\tan }=\left[K_{\gamma w_{b}}\right]+b \int_{0}^{l_{e}}\left\{\frac{T_{21}}{2} w_{b}^{\prime}\left\{H_{L}^{\prime}\right\}\left\lfloor H^{\prime}\right\rfloor+T_{22}\left(w_{b}^{y}+w_{s}^{y}\right)\left\{H_{L}^{\prime}\right\}\left\lfloor H^{\prime}\right\rfloor\right\} d x_{e} \\
& \left(K_{i j}^{2}\right)^{\tan }=\left[K_{\gamma w_{s}}\right]+b \int_{0}^{l_{e}}\left\{\frac{T_{21}}{2} w_{s}^{\prime}\left\{H_{L}^{\prime}\right\}\left\lfloor H^{\prime}\right\rfloor+T_{22}\left(w_{b}^{y}+w_{s}^{y}\right)\left\{H_{L}^{\prime}\right\}\left\lfloor H^{\prime}\right\rfloor\right\} d x_{e} \\
& \left(K_{i j}^{25}\right)^{\tan }=K_{i j}^{25} \\
& \left(K_{i j}^{26}\right)^{\tan }=K_{i j}^{26} \\
& \left(K_{i j}^{33}\right)^{\tan }= \\
& {\left[K_{w_{b} w_{b}}\right]+} \\
& b \int_{0}^{l}\left\{T_{11} u^{\prime}\left\{H^{\prime}\right\}\left\lfloor H^{\prime}\right\rfloor+T_{12} \gamma\left\{H^{\prime}\right\}\left\lfloor H^{\prime}\right\rfloor-T_{13} w_{b}^{\prime \prime}\left\{H^{\prime}\right\}\left\lfloor H^{\prime}\right\rfloor-T_{11}\left(w_{b}^{\prime}\right)^{2}\left\{H^{\prime}\right\}\left\lfloor H^{\prime}\right\rfloor-\right. \\
& \frac{T_{31}}{2} w_{b}^{\prime}\left\{H^{\prime}\right\}\left\lfloor H^{\prime}\right\rfloor+\frac{T_{21}}{2}\left(w_{b}^{y}+w_{s}^{y}\right) w_{b}^{\prime}\left\{H^{\prime}\right\}\left\lfloor H^{\prime}\right\rfloor-C_{1} T_{15} w_{b}^{\prime \prime}\left\{H^{\prime}\right\}\left\lfloor H^{\prime}\right\rfloor+ \\
& \frac{T_{11}}{2}\left(w_{s}^{\prime}\right)^{2}\left\{H^{\prime}\right\}\left\lfloor H^{\prime}\right\rfloor-2 T_{14} w_{b}^{y^{\prime}}\left\{H^{\prime}\right\}\left\lfloor H^{\prime}\right\rfloor+T_{12} w_{b}^{y}\left(2 w_{b}^{\prime}+w_{s}^{\prime}\right)\left\{H^{\prime}\right\}\left\lfloor H^{\prime}\right\rfloor- \\
& T_{32} w_{b}^{y}\left\{H^{\prime}\right\}\left\lfloor H^{\prime}\right\rfloor+T_{22}\left(w_{b}^{y}+w_{s}^{y}\right) w_{b}^{y}\left\{H^{\prime}\right\}\left\lfloor H^{\prime}\right\rfloor-2 C_{1} T_{16} w_{s}^{y^{\prime}}\left\{H^{\prime}\right\}\left\lfloor H^{\prime}\right\rfloor+ \\
& 2 T_{12} w_{b}^{\prime} w_{s}^{y}\left\{H^{\prime}\right\}\left\lfloor H^{\prime}\right\rfloor+T_{12} w_{s}^{\prime} w_{s}^{y}\left\{H^{\prime}\right\}\left\lfloor H^{\prime}\right\rfloor-T_{32} w_{s}^{y}\left\{H^{\prime}\right\}\left\lfloor H^{\prime}\right\rfloor+T_{22}\left(w_{b}^{y}+\right. \\
& \left.\left.w_{s}^{y}\right) w_{s}^{y}\left\{H^{\prime}\right\}\left\lfloor H^{\prime}\right\rfloor\right\} d x_{e} \\
& \left(K_{i j}^{34}\right)^{\tan }=\left[K_{w_{b} w_{s}}\right] \\
& +b \int_{0}^{l_{e}}\left\{\frac{T_{11}}{2} w_{b}^{\prime} w_{s}^{\prime}\left\{H_{L}^{\prime}\right\}\left\lfloor H^{\prime}\right\rfloor+\frac{T_{21}}{2}\left(w_{b}^{y}+w_{s}^{y}\right) w_{s}^{\prime}\left\{H^{\prime}\right\}\left\lfloor H^{\prime}\right\rfloor-\frac{T_{31}}{2} w_{s}^{\prime}\left\{H^{\prime}\right\}\left\lfloor H^{\prime}\right\rfloor\right. \\
& +T_{12} w_{b}^{\prime} w_{b}^{y}\left\{H_{L}^{\prime}\right\}\left\lfloor H^{\prime}\right\rfloor+T_{22}\left(w_{b}^{y}+w_{s}^{y}\right) w_{b}^{y}\left\{H^{\prime}\right\}\left\lfloor H^{\prime}\right\rfloor-T_{32} w_{b}^{y}\left\{H^{\prime}\right\}\left\lfloor H^{\prime}\right\rfloor \\
& \left.+T_{12} w_{b}^{\prime} w_{s}^{y}\left\{H^{\prime}\right\}\left\lfloor H^{\prime}\right\rfloor+T_{22}\left(w_{b}^{y}+w_{s}^{y}\right) w_{s}^{y}\left\{H^{\prime}\right\}\left\lfloor H^{\prime}\right\rfloor-T_{32} w_{s}^{y}\left\{H^{\prime}\right\}\left\lfloor H^{\prime}\right\rfloor\right\} d x_{e} \\
& \left(K_{i j}^{35}\right)^{\tan }=\left[K_{w_{b} w_{b}^{y}}\right] \\
& +b \int_{0}^{l_{e}}\left\{T_{21} u^{\prime}\left\{H^{\prime}\right\}\left\lfloor H_{L}\right\rfloor+T_{22} \gamma\left\{H^{\prime}\right\}\left\lfloor H_{L}\right\rfloor-T_{23} w_{b}^{\prime \prime}\left\{H^{\prime}\right\}\left\lfloor H_{L}\right\rfloor+\frac{T_{21}}{2}\left(w_{b}^{\prime}\right)^{2}\left\{H^{\prime}\right\}\left\lfloor H_{L}\right\rfloor\right. \\
& -C_{1} T_{25} w_{s}^{\prime \prime}\left\{H^{\prime}\right\}\left\lfloor H_{L}\right\rfloor+\frac{T_{21}}{2}\left(w_{s}^{\prime}\right)^{2}\left\{H^{\prime}\right\}\left\lfloor H_{L}\right\rfloor+T_{22}\left(w_{b}^{\prime}+w_{s}^{\prime}\right) w_{b}^{y}\left\{H^{\prime}\right\}\left\lfloor H_{L}\right\rfloor \\
& \left.+T_{22}\left(w_{b}^{\prime}+w_{s}^{\prime}\right) w_{s}^{y}\left\{H^{\prime}\right\}\left\lfloor H_{L}\right\rfloor\right\} d x_{e}
\end{aligned}
$$




$$
\begin{aligned}
& \left(K_{i j}^{36}\right)^{\tan }=\left[K_{w_{b} w_{s}^{y}}\right] \\
& +b \int_{0}^{l_{e}}\left\{T_{21} u^{\prime}\left\{H^{\prime}\right\}\left\lfloor H_{L}\right\rfloor+T_{22} \gamma\left\{H^{\prime}\right\}\left\lfloor H_{L}\right\rfloor-T_{23} w_{b}^{\prime \prime}\left\{H^{\prime}\right\}\left\lfloor H_{L}\right\rfloor+\frac{T_{21}}{2}\left(w_{b}^{\prime}\right)^{2}\left\{H^{\prime}\right\}\left\lfloor H_{L}\right\rfloor\right. \\
& -C_{1} T_{25} w_{s}^{\prime \prime}\left\{H^{\prime}\right\}\left\lfloor H_{L}\right\rfloor+\frac{T_{21}}{2}\left(w_{s}^{\prime}\right)^{2}\left\{H^{\prime}\right\}\left\lfloor H_{L}\right\rfloor+T_{22}\left(w_{b}^{\prime}+w_{s}^{\prime}\right) w_{b}^{y}\left\{H^{\prime}\right\}\left\lfloor H_{L}\right\rfloor \\
& \left.+T_{22}\left(w_{b}^{\prime}+w_{s}^{\prime}\right) w_{s}^{y}\left\{H^{\prime}\right\}\left\lfloor H_{L}\right\rfloor\right\} d x_{e} \\
& \left(K_{i j}^{44}\right)^{\tan }= \\
& {\left[K_{w_{s} w_{s}}\right]+} \\
& b \int_{0}^{l}\left\{T_{11} u^{\prime}\left\{H^{\prime}\right\}\left\lfloor H^{\prime}\right\rfloor+T_{12} \gamma\left\{H^{\prime}\right\}\left\lfloor H^{\prime}\right\rfloor-T_{13} w_{b}^{\prime \prime}\left\{H^{\prime}\right\}\left\lfloor H^{\prime}\right\rfloor-\frac{T_{11}}{2}\left(w_{b}^{\prime}\right)^{2}\left\{H^{\prime}\right\}\left\lfloor H^{\prime}\right\rfloor-\right. \\
& C_{1} T_{15} w_{s}^{\prime \prime}\left\{H^{\prime}\right\}\left\lfloor H^{\prime}\right\rfloor+T_{11}\left(w_{s}^{\prime}\right)^{2}\left\{H^{\prime}\right\}\left\lfloor H^{\prime}\right\rfloor+\frac{T_{11}}{2}\left(w_{b}^{y}+w_{s}^{y}\right) w_{s}^{\prime}\left\{H^{\prime}\right\}\left\lfloor H^{\prime}\right\rfloor- \\
& C_{1} \frac{T_{51}}{2} w_{s}^{\prime}\left\{H^{\prime \prime}\right\}\left\lfloor H^{\prime}\right\rfloor-2 T_{14} w_{b}^{y^{\prime}}\left\{H^{\prime}\right\}\left\lfloor H^{\prime}\right\rfloor+T_{12} w_{b}^{\prime} w_{b}^{y}\left\{H^{\prime}\right\}\left\lfloor H^{\prime}\right\rfloor+ \\
& 2 T_{12} w_{s}^{\prime} w_{b}^{y}\left\{H^{\prime}\right\}\left\lfloor H^{\prime}\right\rfloor+T_{22}\left(w_{b}^{y}+w_{s}^{y}\right) w_{b}^{y}\left\{H^{\prime}\right\}\left\lfloor H^{\prime}\right\rfloor-C_{1} T_{52} w_{b}^{y}\left\{H^{\prime \prime}\right\}\left\lfloor H^{\prime}\right\rfloor- \\
& 2 C_{1} T_{16} w_{s}^{y^{\prime}}\left\{H^{\prime}\right\}\left\lfloor H^{\prime}\right\rfloor+T_{12} w_{b}^{\prime} w_{s}^{y}\left\{H^{\prime}\right\}\left\lfloor H^{\prime}\right\rfloor+2 T_{12} w_{s}^{\prime} w_{s}^{y}\left\{H^{\prime}\right\}\left\lfloor H^{\prime}\right\rfloor+T_{22}\left(w_{b}^{y}+\right. \\
& \left.\left.w_{s}^{y}\right) w_{s}^{y}\left\{H^{\prime}\right\}\left\lfloor H^{\prime}\right\rfloor-C_{1} T_{52} w_{s}^{y}\left\{H^{\prime \prime}\right\}\left\lfloor H^{\prime}\right\rfloor\right\} d x_{e} \\
& \left(K_{i j}^{45}\right)^{\tan }=\left[K_{w_{s} w_{b}^{y}}\right] \\
& +b \int_{0}^{l_{e}}\left\{T_{21} u^{\prime}\left\{H^{\prime}\right\}\left\lfloor H_{L}\right\rfloor+T_{22} \gamma\left\{H^{\prime}\right\}\left\lfloor H_{L}\right\rfloor-T_{23} w_{b}^{\prime \prime}\left\{H^{\prime}\right\}\left\lfloor H_{L}\right\rfloor+\frac{T_{21}}{2}\left(w_{b}^{\prime}\right)^{2}\left\{H^{\prime}\right\}\left\lfloor H_{L}\right\rfloor\right. \\
& -C_{1} T_{25} w_{s}^{\prime \prime}\left\{H^{\prime}\right\}\left\lfloor H_{L}\right\rfloor+\frac{T_{21}}{2}\left(w_{s}^{\prime}\right)^{2}\left\{H^{\prime}\right\}\left\lfloor H_{L}\right\rfloor+T_{22}\left(w_{b}^{\prime}+w_{s}^{\prime}\right) w_{b}^{y}\left\{H^{\prime}\right\}\left\lfloor H_{L}\right\rfloor \\
& \left.+T_{22}\left(w_{b}^{\prime}+w_{s}^{\prime}\right) w_{s}^{y}\left\{H^{\prime}\right\}\left\lfloor H_{L}\right\rfloor\right\} d x_{e} \\
& \left(K_{i j}^{46}\right)^{\tan }=\left[K_{w_{s} w_{s}^{y}}\right] \\
& +b \int_{0}^{l_{e}}\left\{T_{21} u^{\prime}\left\{H^{\prime}\right\}\left\lfloor H_{L}\right\rfloor+T_{22} \gamma\left\{H^{\prime}\right\}\left\lfloor H_{L}\right\rfloor-T_{23} w_{b}^{\prime \prime}\left\{H^{\prime}\right\}\left\lfloor H_{L}\right\rfloor+\frac{T_{21}}{2}\left(w_{b}^{\prime}\right)^{2}\left\{H^{\prime}\right\}\left\lfloor H_{L}\right\rfloor\right. \\
& -C_{1} T_{25} w_{s}^{\prime \prime}\left\{H^{\prime}\right\}\left\lfloor H_{L}\right\rfloor+\frac{T_{21}}{2}\left(w_{s}^{\prime}\right)^{2}\left\{H^{\prime}\right\}\left\lfloor H_{L}\right\rfloor+T_{22}\left(w_{b}^{\prime}+w_{s}^{\prime}\right) w_{b}^{y}\left\{H^{\prime}\right\}\left\lfloor H_{L}\right\rfloor \\
& \left.+T_{22}\left(w_{b}^{\prime}+w_{s}^{\prime}\right) w_{s}^{y}\left\{H^{\prime}\right\}\left\lfloor H_{L}\right\rfloor\right\} d x_{e} \\
& \left(K_{i j}^{55}\right)^{\tan }=\left[K_{w_{b}} w_{b}^{y}\right] \\
& \left(K_{i j}^{56}\right)^{\tan }=\left[K_{w_{b}} w_{s}^{y}\right] \\
& \left(K_{i j}^{66}\right)^{\tan }=\left[K_{w_{s}} w_{s}^{y}\right]
\end{aligned}
$$




\subsection{Boundary Conditions}

The boundary conditions considered in this research are given below.

\subsubsection{Boundary Conditions for HSDT}

In the formulation based on HSDT, $, \gamma, w_{b}, w_{b}^{\prime}, w_{s}, w_{s}^{\prime}, w_{b}^{y}$ and $w_{s}^{y}$ are the end nodal degrees of freedom. The boundary conditions for a pinned end is

$$
u=w_{b}=w_{s}=w_{b}^{y}=w_{s}^{y}=0
$$

\subsubsection{Boundary Conditions for Cylindrical Bending}

In the formulation based on Cylindrical Bending, $u, w$ and $w^{\prime}$ are the end nodal degrees of freedom. The boundary conditions for a pinned end is

$$
u=w=0
$$




\section{$4 \quad$ RESULTS and DISCUSSION}

A code is written in MATLAB to solve the nonlinear finite element equations of beam bending based on HSDT using the Newton-Raphson technique. The formulation and the code are verified first by considering a simpler large-deflection problem of cylindrical bending of plates and comparing with existing solutions. The present results for the HSDT case of large deflection are for a pinned-pinned composite beam subjected to positive and negative uniformlydistributed loads; a comparison with the linear case is also made.

\subsection{Cylindrical Bending Verification}

The MATLAB code incorporating the Newton-Raphson iterative technique for nonlinear analysis is verified by solving the large-deflection problem of cylindrical bending considered by Sun and Chin (1988). The problem consists of a pinned-pinned rectangular composite laminated plate, $\left[\mathrm{O}_{4} / \mathrm{9O}_{4}\right]$, subjected to a uniform transverse load. The material properties of the graphite-epoxy composite are presented in Table 4.1 as follows

Table 4.1 Material properties [Sun and Chin (1988)]

\begin{tabular}{|l|l|}
\hline Property & Value \\
\hline Composite & Graphite-epoxy \\
\hline$E_{1}(\mathrm{msi})$ & 20 \\
\hline$E_{2}(\mathrm{msi})$ & 1.4 \\
\hline$V_{12}$ & 0.3 \\
\hline$G_{12}, G_{13}, G_{23}(\mathrm{msi})$ & 0.7 \\
\hline
\end{tabular}

The geometric properties of the composite beam are tabulated in Table 4.2

Table 4.2 Geometric properties [Sun and Chin (1988)]

\begin{tabular}{|l|l|}
\hline Property & Value \\
\hline Length, $L$ (in.) & 9 \\
\hline Width, $b$ (in.) & 0.05 \\
\hline Total thickness of beam, $h($ in.) & 0.04 \\
\hline Lay-ups considered & {$\left[0_{4} / 90_{4}\right]$} \\
\hline
\end{tabular}

The composite laminated pinned-pinned beam is discretized into four elements with three internal nodes each. The beam is subjected to an axial load of $1 \mathrm{lb} / \mathrm{in}$. The Newton-Raphson iterative method is employed to find out the deflection as the function of position of beam. Figure 4.1 shows the out-of-plane non-dimensional deflection $(w / h)$ along the non-dimensional length of beam $(x / L)$ when subjected to the axial load of $1 \mathrm{lb} / \mathrm{in}$. 


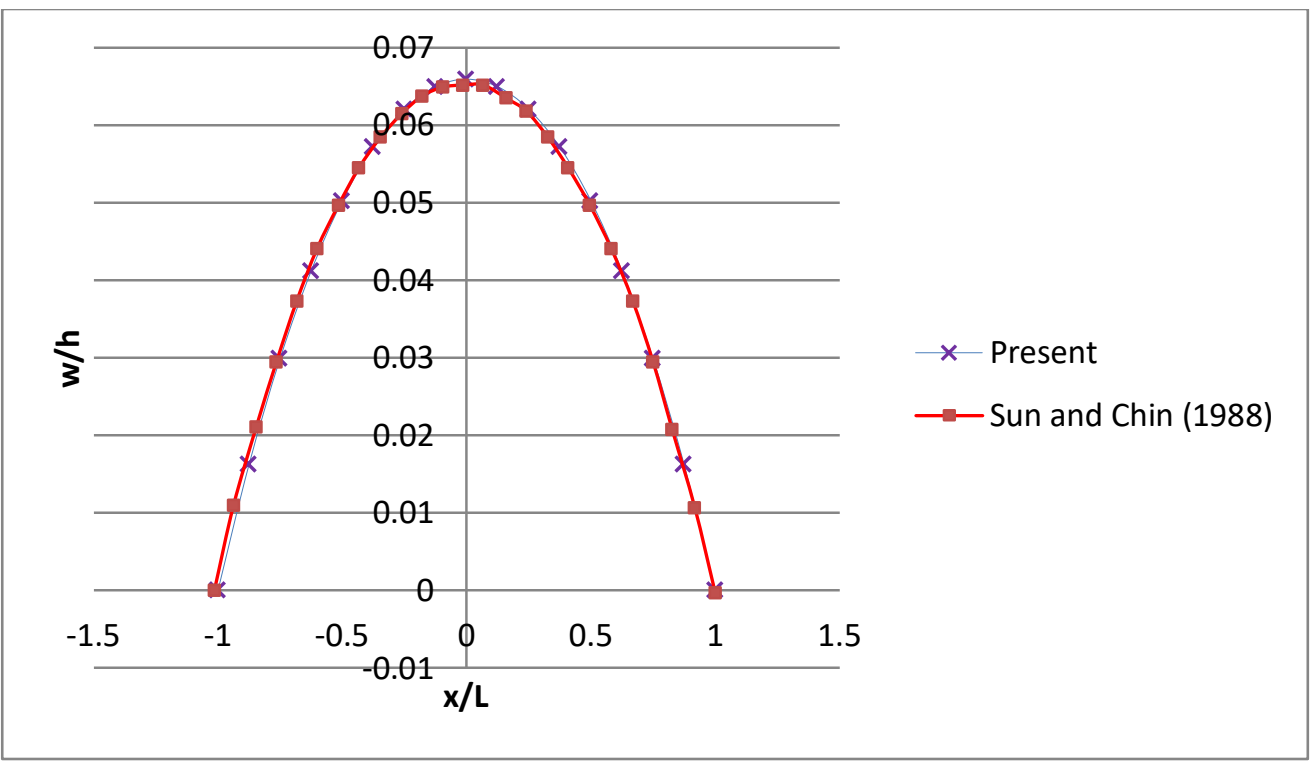

Fig. 4.1 Out-of-plane deflection of $\left[0_{4} / 90_{4}\right]$ laminate subjected to uniform in-plane load $N_{x}=1 \mathrm{lb} / \mathrm{in}$

The comparison indicates that the present result agrees well with that of Sun and Chin (1988). The maximum normalized transverse deflection for $N_{x}=1 \mathrm{lb} / \mathrm{in}$. is 0.006587 .

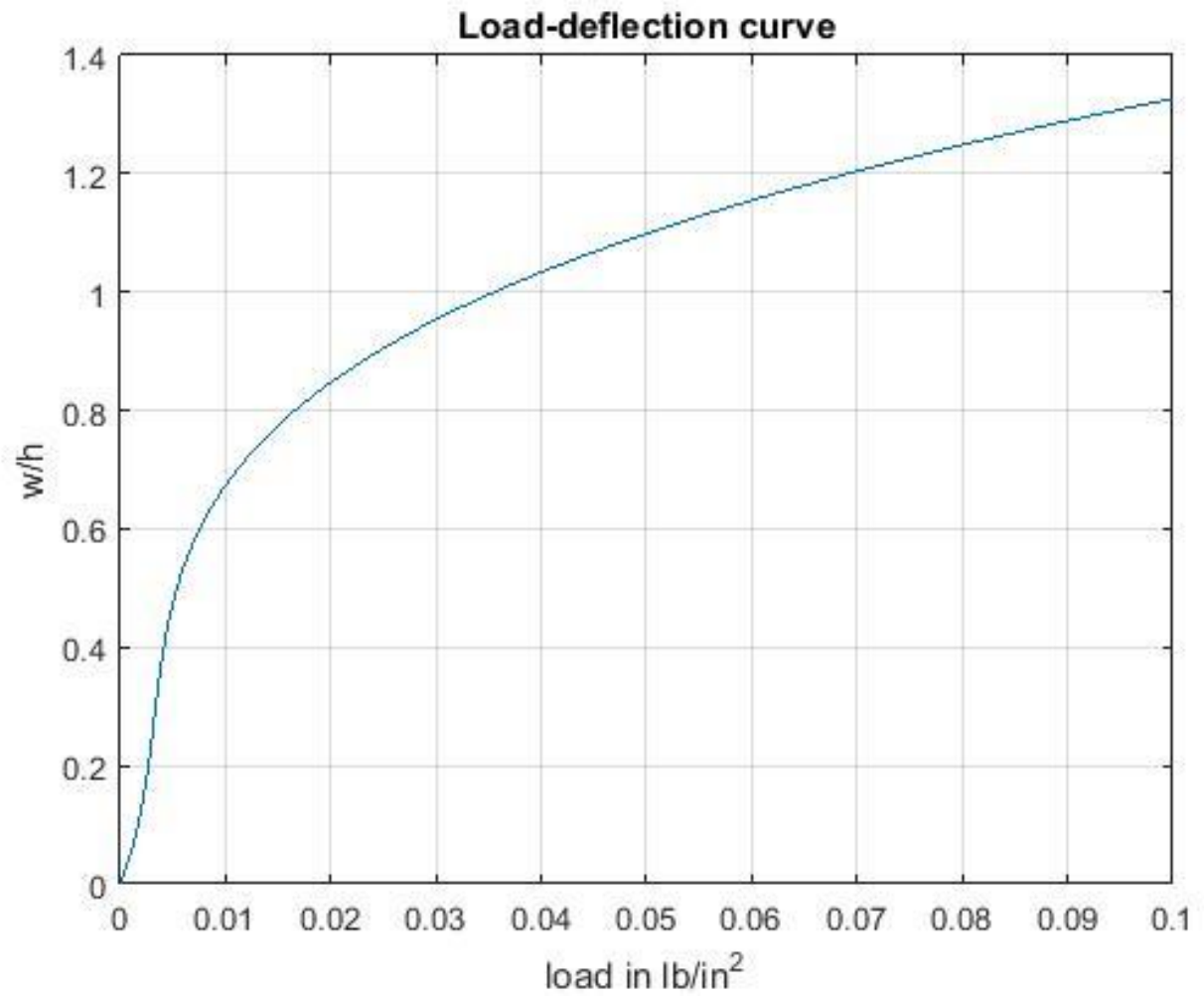

Fig. 4.2Load-deflection curveof a pinned-pinned composite beam under transverse load 
The second verification case pertains to a pinned-pinned beam with the same material and geometric properties and the same lay up as before but the loading is a uniform transverse load. Figure 4.2 shows the plot of the normalized maximum deflection $\left(w_{0} / h\right)$ as a function of the load intensity. . The graph is plotted for the load varying from 0 to $0.1 \mathrm{lb} /$ in. $^{2}$. Table 4.2 presents the comparison between the analytical results of Reddy (1997) and the present work. The results show that the agreement between the two sets of results is excellent.

Table 4.3 Transverse deflections, $w_{0} / h$, of cylindrical bending of a $\left[0_{4} / 90_{4}\right]$ laminate under uniformly distributed transverse load

\begin{tabular}{|c|c|c|c|}
\hline Load & Reddy(1997) & $\begin{array}{l}\text { Present } \\
\text { work }\end{array}$ & Error\% \\
\hline $\mathrm{p}_{0}\left(\mathrm{lb} / \mathrm{in}^{2}{ }^{2}\right)$ & $\mathrm{w}_{0} / \mathrm{h}$ & $\mathrm{w}_{0} / \mathrm{h}$ & \\
\hline 0.005 & 0.475 & 4.76E-01 & -0.13173 \\
\hline 0.01 & 0.673 & 6.74E-01 & -0.08194 \\
\hline 0.02 & 0.847 & 8.47E-01 & -0.04091 \\
\hline 0.03 & 0.954 & 9.54E-01 & 0.049898 \\
\hline 0.04 & 1.034 & $1.03 E+00$ & 0.047046 \\
\hline 0.05 & 1.1 & $1.10 \mathrm{E}+00$ & 0.101879 \\
\hline 0.1 & 1.327 & $1.33 \mathrm{E}+00$ & 0.046439 \\
\hline
\end{tabular}

\subsection{HSDT Result}

The present result is for a $\left[90_{8} / 0_{8}\right]$ pinned-pinned beam based on the HSDT formulation subjected to a uniformly-distributed load. The material and geometric properties are given in Tables 4.4 and 4.5 , respectively. Figure 4.3 shows the plot of the maximum deflection as a function of the transverse load for the range of $-0.007 \mathrm{~N} / \mathrm{mm}$ to $+0.03 \mathrm{~N} / \mathrm{mm}$. The results are presented in Table 4.6 also. For the sake of comparison, the linear solution is also presented in Fig. 4.3 and Table 4.6. It can be seen that the nonlinear solution varies considerably from that of the linear solution; at the load value of $0.03 \mathrm{~N} / \mathrm{mm}$, the nonlinear deflection is less by $42 \%$.

Table 4.4 Material properties

\begin{tabular}{|l|l|}
\hline Property & Value \\
\hline$E_{1}(\mathrm{GPa})$ & 144.8 \\
\hline$E_{1} / E_{2}$ & 40 \\
\hline$V_{12}$ & 0.25 \\
\hline$G_{12} / E_{2}, G_{13} / E_{2}$ & 0.5 \\
\hline$G_{23} / E_{2}$ & 0.4 \\
\hline
\end{tabular}


Table 4.5 Geometric properties

\begin{tabular}{|l|l|}
\hline Property & Value \\
\hline Length, $L(\mathrm{~mm})$ & 115.47 \\
\hline Width, $b(\mathrm{~mm})$ & 3.00 \\
\hline Total thickness of beam, $h(\mathrm{~mm})$ & 2.00 \\
\hline Lay-ups considered & {$\left[90_{8} / 0_{8}\right]$} \\
\hline
\end{tabular}

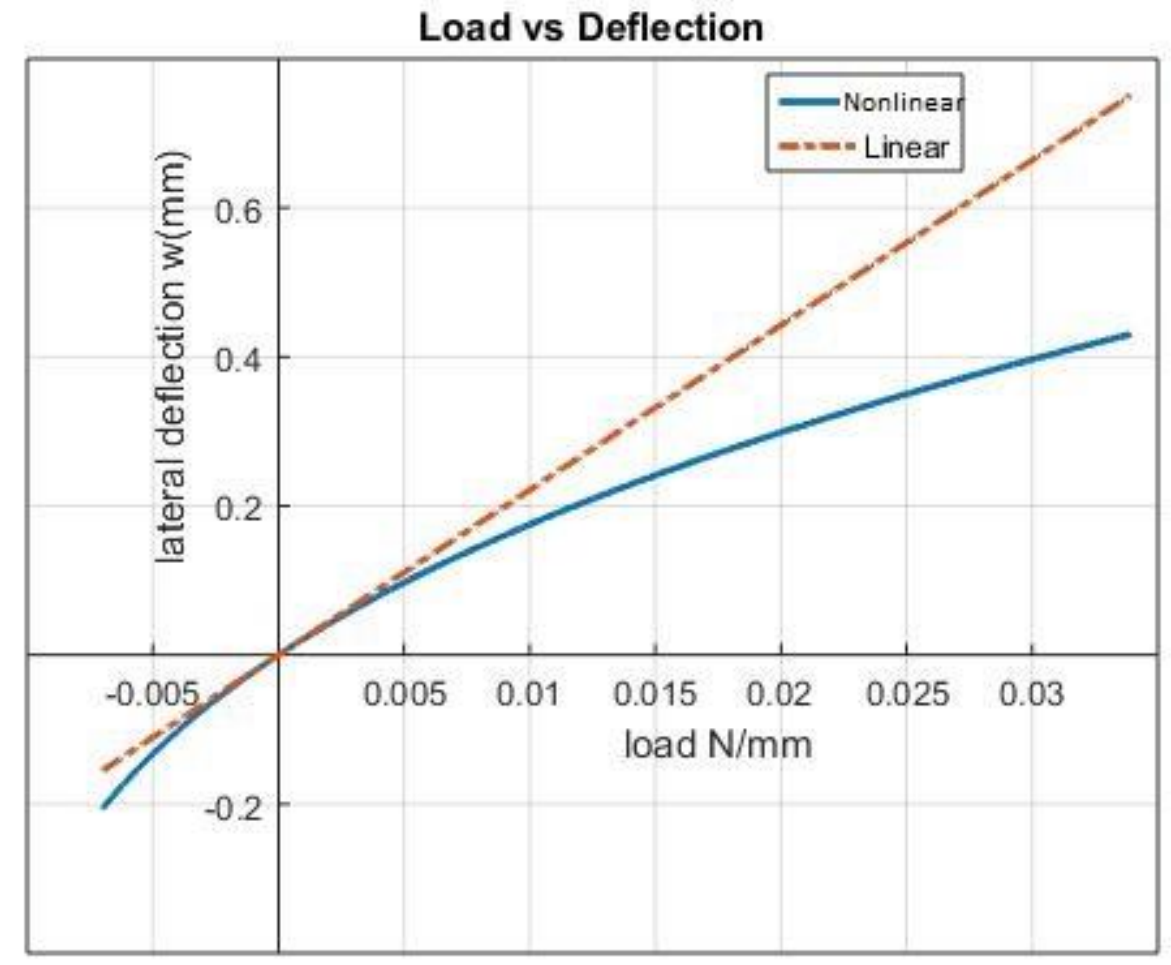

Fig. 4.3 Load-deflection curve for nonlinear and linear with pinned-pinned edges

Table 4.6 Transverse deflections, $w_{\text {max }}$ of nonlinear and linear of a $\left[90_{8} / 0_{8}\right]$ laminate under uniformly distributed transverse load

\begin{tabular}{|r|r|r|}
\hline \multicolumn{1}{|l|}{ Load } & \multicolumn{1}{|l|}{ Nonlinear } & \multicolumn{1}{l|}{ Linear } \\
\hline $\begin{array}{c}p_{0} \\
(\mathrm{~N} / \mathrm{mm})\end{array}$ & $\mathrm{w}_{\max }(\mathrm{mm})$ & $\mathrm{w}_{\max }(\mathrm{mm})$ \\
\hline-0.007 & -0.206 & -0.155 \\
\hline-0.006 & -0.167 & -0.133 \\
\hline-0.005 & -0.133 & -0.111 \\
\hline
\end{tabular}




\begin{tabular}{|c|c|c|}
\hline-0.004 & -0.102 & -0.089 \\
\hline-0.003 & -0.073 & -0.066 \\
\hline-0.002 & -0.047 & -0.044 \\
\hline-0.001 & -0.023 & -0.022 \\
\hline 0 & 0.000 & 0.000 \\
\hline 0.001 & 0.021 & 0.022 \\
\hline 0.002 & 0.042 & 0.044 \\
\hline 0.003 & 0.061 & 0.066 \\
\hline 0.004 & 0.079 & 0.089 \\
\hline 0.005 & 0.097 & 0.111 \\
\hline 0.006 & 0.114 & 0.133 \\
\hline 0.007 & 0.130 & 0.155 \\
\hline 0.008 & 0.146 & 0.177 \\
\hline 0.009 & 0.161 & 0.199 \\
\hline 0.01 & 0.175 & 0.221 \\
\hline 0.011 & 0.189 & 0.243 \\
\hline 0.012 & 0.203 & 0.266 \\
\hline 0.013 & 0.216 & 0.288 \\
\hline 0.014 & 0.229 & 0.310 \\
\hline 0.015 & 0.241 & 0.332 \\
\hline 0.016 & 0.253 & 0.354 \\
\hline 0.017 & 0.265 & 0.376 \\
\hline 0.018 & 0.276 & 0.398 \\
\hline 0.019 & 0.288 & 0.420 \\
\hline 0.02 & 0.299 & 0.443 \\
\hline 0.021 & 0.309 & 0.465 \\
\hline 0.022 & 0.320 & 0.487 \\
\hline 0.023 & 0.330 & 0.509 \\
\hline 0.024 & 0.340 & 0.531 \\
\hline 0.025 & 0.350 & 0.553 \\
\hline 0.026 & 0.360 & 0.575 \\
\hline 0.027 & 0.369 & 0.598 \\
\hline 0.028 & 0.379 & 0.620 \\
\hline 0.029 & 0.388 & 0.642 \\
\hline 0.03 & 0.397 & 0.664 \\
\hline 0.031 & 0.405 & 0.686 \\
\hline 0.032 & 0.414 & 0.708 \\
\hline 0.033 & 0.423 & 0.730 \\
\hline
\end{tabular}




\subsection{Accomplishments and Conclusions}

- Successfully formulated the large deflection bending of a composite beam based on HSDT.

- Derived the nonlinear part of the element stiffness matrix based on an $h-p$ version finite element method.

- Derived the tangential stiffness matrix for use in the Newton-Raphson iterative technique.

- Verified the MATLAB code by considering examples of large-deflection of simple cylindrical bending of composite plates.

- It is seen that the nonlinear deflection varies considerably from that of the linear solution and this could play a crucial part in the design of large-deflection structures.

\subsection{Future Work}

- Perform a parametric analysis by considering different lay ups, different fiber-volume fractions, different types of end conditions, and different types of loads.

- Determine the stresses across the thickness of the laminate at critical cross sections; this would make sure one does not artificially consider large values of the applied load (as the other authors have done), while the beam would have long failed.

- Perform a dynamic analysis.

- Apply to practical cases such as a helicopter blade. 


\section{References}

Barbero,E.J.,2010,“IntroductiontoCompositeMaterialsDesign,"SecondEdition,TaylorandFran cis, Philadelphia.

Bathe, K.J., 1979, "Finite element formulation, modeling and solution of nonlinear dynamic problems," in: Numerical methods for partial differential equations (Academic Press, 1979)

I-40

Bathe, K.J. and Cimento, A.P., 1980, "Procedures for the Solution of Nonlinear Finite Element Equations," Computer Methods in Applied Mechanics and Engineering, Vol. 22, pp. 59-85

Bathe, K.J., 1976, "An assessment of current solution capabilities for nonlinear problems in solid mechanics," Numerical methods for partial differential equations III" (Academic Press, 1976) pp. 117-164

Bathe, K.J., RammE. and Wilson, E.L., 1973, "Finite element formulations for large deformation dynamic analysis," International Journal for Numerical Methods in Engineering Vol. 9, pp. 353-386

Bisshopp, K.E and Drucker D.C.,1945, "Numerical results from Large Deflection of Beams and frames Analysed by Means of Elliptic Integrals," Quarterly of Applied mathematics, Vol. 3, No. 3, pp. 272-275"

Chandrasekaran, G. and Sivaneri, N.T., 2000, "Dynamic Analysis of Composite Moving Beams," Master's Thesis, West Virginia University, Morgantown, WV

Cowper, G.R., 1996, "Shear Coefficient in Timoshenko Beam Theory," Journal of Applied Mechanics, Vol. 33, pp. 335-340

Felippa, C.A., 1976, "Procedures for computer analysis of large nonlinear structural systems,

Proceedings," International Symposium on Large Engineering Systems, Univ. Manitoba, Winnipeg, Canada

Hanif, M. and Sivaneri, N.T., 2016, "Hygrothermal Analysis of Composite Beams under Moving Loads," American Society of Composite Comference, September 19-21, 2016, Williamsburg, VA

Howell, Midha, 1995, "Parametric Deflection Approximations for End-Loaded, Large Deflections Beams," Journal of Mechanical Design, Vol. 117, pp.156-165 
Koo,J.S. and Kwak, B.M., "Laminated Composite Beam Element Separately Interpolated For

The Bending And Shear Deformations Without Increase In Nodal DOF,"Computers and Structures, Vol. 53, No. 5, pp. 1091-1098

Levinson, M., 1981, “A New Rectangular Beam Theory,"Journal of sound Vibrations, Vol. 74, pp. $81-87$

Lo, K.H., Christensen, R.M. and Wu E.M., 1977, "Higher-Order Theory of Plate Deformation, Part2: Laminated Plates,"Journal of applied Mechanics, ASME 44, pp. 669-676

Mattiasson, K.,1981, "Numerical results from Large Deflection of Beams and frames Analysed by Means of Elliptic Integrals,"International Journal of Numerical Methods in Engineering, Vol. 7, No. 1, pp. 145-153

Polina, G. and Sivaneri,N.T., 2014, "Vibration Attenuation of Composite Moving Beams using Active Vibration Control",American Society of Composites Conference, September 8-10, 2014, San Diego, CA

Reddy, J.N., 1984, "Simple higher-order theory for laminated composite", Journal of applied Mechanics, Vol. 51, pp. 745-752

Reddy,J.N.,1997,“MechanicsofLaminatedCompositePlates:TheoryandAnalysis,"Second Edition, CRC Press, BocaRaton, Fla.

Sivaneri, N.T. and Hanif, M., 2016, "Failure Analysis of Composite Beams under Moving Loads," American Society of Composites Conference, September 19-21, 2016, Williamsburg, VA.

Sivaneri, N.T. and Nagappan, G., 2012, "Axially-Moving Composite Beams using HigherOrder Shear-Deformation Theory," 53rd AIAA/ASME/ASCE/AHS/ASC Structures, Structural Dynamics and Materials Conference, April 23-26, 2012, Honolulu, HI.

Sivaneri, N.T. and Vennam, S., 2010, "Hygrothermal Analysis of Rotating Composite Beam," World Journal of Engineering, pp. 343

Sreeram, T.R. and Sivaneri, N.T., 19977, "FE Analysis of Moving Beam using Lagrangian Multiplier Method", International Journal of Solids and structures, Vol. 35, No. 28-29, pp. 3675-3694

Stemple, A.D. and Lee, S.W., 1989, “A Finite element Model for Composite beams under large Deflection with Arbitrary Cross-Sectional Warping", International journal for Numerical Methods in Engineering, Vol. 28, pp. 2143-2160 
Sun, C.T. and Chin,H., 1988, "Analysis of Asymmetric Composite Laminate," AIAA Journal, Vol. 26, No. 6, pp. 714-718

Vlachoutsis, S., 1992, "Shear Correction Factor for Plates and Shells," International Journal of Numerical Methods, Vol. 33, pp. 1537-1552

Vo, T.P. and Lee J., 2010, "Geometric Nonlinear Analysis of Thin-walled Composite Beams using FEM based on FSDT," Rep, Department of Architectural Engineering, Sejong University, Seoul, Korea 